\title{
Maximum yield fishing and optimal fleet composition. A stage structured model analysis with an example from the Norwegian North-East Arctic cod fishery
}

\author{
Irmelin Slettemoen Helgesen \\ Economic Department Norwegian University of Science and Technology (NTNU), \\ Trondheim, Norway \\ Anders Skonhoft \\ Economic Department Norwegian University of Science and Technology (NTNU), \\ Trondheim, Norway \\ and
}

Arne Eide

Norwegian College of Fishery Science, University of Troms $\varnothing$, Troms $\varnothing$, Norway

\section{Abstract}

A stage structured fishery model with three stages; recruits, immature fish and mature fish is formulated and utilised to analyse maximum sustainable yield (MSY) and optimal harvesting composition in a fishery with two heterogeneous fleets. The stage structured model developed bundles the age classes found in age structured models into stage classes based on their level of maturity, but also the pattern according to which they are harvested. Two fleets, high sea and coastal vessels, harvest respectively the immature and mature stages. The maximum sustainable yield (MSY) is studied in light of both perfect and imperfect fishing selectivity. In addition, we analyse the biomass loss of a sharing rule where the high sea trawler fleet is granted a certain share of the harvested biomass. The paper provides a theoretical extension to the literature on age structured models, and presents several new analytical results related to stage structured models which are supported by a numerical illustration inspired by the NorthEast Arctic cod fishery.

Keywords: Fishery management, stage structure, maximum yield harvesting, sharing rule, selectivity 


\section{Introduction}

The use of age structured fishery models is common when studying optimal harvest compositions; that is, which of the population's year classes and how much is it beneficial to harvest. Some recent publications on this include Tahvonen (2008), Skonhoft et al. (2012), Quaas et al. (2013), Diekert et al. (2010a; 2010b), Diekert (2013) and Skonhoft and Gong (2014). In line with the result of the well-known Reed (1980) paper, when the objective is maximum sustainable yield (MSY), the general finding is to prioritise the harvest of larger mature fish. As harvest costs generally differ between the vessel groups targeting different year classes, the outcome is more ambiguous when such costs are included. For instance, if the unit harvest cost is relatively high when targeting mature fish and relatively lower while targeting the young fish, the above result may be reversed (Skonhoft et al. 2012). The inclusion of dynamics, or the issue of selectivity, further complicates the outcome, see Hannesson (1975) and Tahvonen (2009). In line with Hannesson's results Tahvonen finds pulse fishing to be the optimal strategy. Pulse fishing may however involve high social and private costs that are not accounted for (e.g., idle harvest capacity, work instability of fishers, etc.). Diekert et al., (2010a; 2010b) and Diekert (2013) also use an age structured model to find that it is optimal to spare the young, though their inclusion of gear selectivity as a control enable a steady harvest.

In reality, however, fishermen, or fishing vessels, rarely operate with perfect gear selectivity, and thus they do not have the option to only harvest fish that are, e.g. eight years old. Instead, it may make more sense to characterise the population by stages where each stage class typically consist of several age classes. This is what is done in the present paper, which is motivated by the North-East Arctic (NEA) cod (Gadus morhua) fishery, the world's largest cod fishery with a harvest of 864000 tonnes in 2015 (Anon. 2016). The vessels exploiting the NEA cod fishery can be categorised as two fleets; the coastal fleet with conventional fishing gear and the high sea trawler fleet. Due to different gear, as well as restrictions on harvesting area, the coastal fleet mainly harvest the mature and spawning fish, typically comprising fish of six years and older, while the trawler fleet mainly harvest younger, immature fish, typically comprising age classes three to six. The main goal of our paper is to analyse the optimal harvesting composition of mature and immature fish under different conditions, and relate these findings to our construction of a stage model. 
In the bioeconomic literature there are to our best knowledge few, if any, models aiming to analyse optimal harvesting composition in stage structured models. Caswell (2001, Ch. 4) and Getz and Haight (1989) study stage structured models, and derive the main differences in comparison to age structured models. However, both these books are mainly concerned with biological issues. Our model is analysed with different assumptions about fishing selectivity, and fleet sharing rules. The latter refers to politically determined rules concerning how the harvest is shared between various vessel groups. Currently the Norwegian share of the NEA cod is allocated between the trawlers and the coastal fleet according to the so-called trawl ladder; a sharing rule that, depending on the size of the TAC, determines the allocation of the TAC between the two fleets.

A number of studies have analysed the population dynamics and fleet economics of the NEA cod fishery. Several of these studies discuss interactions and trade-offs between different user groups (as for example trawlers and coastal boats, different nations, gillnetters and trawlers, etc.). Sumaila (1997) use a game theoretic framework in combination with an age structured population model, to study cooperation and non-cooperation between the trawlers and the coastal fleet. The same system is analysed by Zimmerman et al. (2011) who find that, with size-dependent pricing, it is optimal to target larger (older) individuals combined with a lower harvesting rate. Using a type of prey-predator model for cannibalism Eide and Wikan (2010) examine a fishery targeting the mature stock with bycatch of immatures. With gear selectivity as a control, they find that although it would be optimal to reduce total fishing mortality, the share of immatures harvested should be increased. Using a two-stage biomass model Armstrong (1999) analyses the optimal harvest composition between the coastal and trawler fleet. She does not find any biological or economic justification for the structure of the trawl ladder.

This paper only studies Maximum Sustainable Yield (MSY) fishing, or the dynamic equivalent, which we label Maximum Yield (MY) fishing. It is well known that MY fishing in equilibrium, or steady state, coincides with MSY fishing for zero discount rate. While this is, as indicated, a simplification compared to the maximum economic yield (MEY) problem where costs are included, and a narrow goal that does not account for social welfare or ecosystem services, our choice is also motivated by the fact that fishery managers frequently regard MSY as the relevant management goals. MSY is for instance, the goal set by the EU Common Fishery Policy (CFP) and the United Nations Convention on the Law of the Sea, 
which is ratified by Norway (http://europa.eu/rapid/press-release_MEMO-13-1125_en.htm, http://www.un.org/depts/los/convention_agreements/convention_overview_fish_stocks.htm). See also the discussion in Wilen (2000). Within the given framework, we aim to find and characterise the optimal harvest composition, and to examine the driving forces behind the exploitation scheme, both with and without bycatch. The social cost in terms of biomass loss of applying a sharing rule for the two fleets is also examined. The paper provides several results concerning the harvest of populations subject to imperfect selectivity and sharing rules which in most cases will coincide what we find in age structured models.

Section two gives first a brief overview of the Norwegian North-East Arctic cod fishery and in section three the stage structured biological model is formulated. Our notion of fishing selectivity is described in section four. Throughout the paper we implicitly assume a Baranov catch function for both fleets (see, e.g., Quinn 2003), indicating that the fishing mortalities always are below one. In section five, we first analyse the fishery assuming perfect harvesting selectivity, followed by section six where the case of imperfect selectivity is studied. In section seven a numerical illustration is provided, while we in section eight introduce the sharing rule where the trawler fleet is guaranteed a minimum fraction of the harvested biomass. The outcome here is also supported by a numerical illustration. Section nine finally summarises our findings.

\section{The Norwegian North-East Arctic Cod Fishery}

The North-East Arctic (NEA) cod is the world's largest cod stock, with an estimated stock size of 4.2 million tonnes in 2015 (Anon. 2016). It follows that the stock is considered to be reasonably well managed, an achievement due to the two sharing nations Russia and Norway's joint management effort (Eide et al. 2013; Armstrong et al. 2014). In 2015 the TAC was 894000 tonnes, and Norway receives about 45 percent of this, in fact the Norwegian fleet harvested and sold cod for over 500 million NOK in 2015. This harvest of NEA cod accounts for about one-half of the total Norwegian harvest in demersal fisheries, and in 2015 the average Norwegian demersal fishing vessel had an operating profit of about 1,190 thousand NOK (http://www.fiskeridir.no/Yrkesfiske/Statistikk-

yrkesfiske/Loennsomhet). That said, the fishery's lack of realised resource rent suggests an inefficient harvesting pattern, both due to quotas above the scientific advice and a shift 
towards the harvest of younger age classes (Steinshamn, 2005; Arnason et al., 2004; Ottersen, 2008; Gullestad et al., 2015)

The NEA cod stock is characterised by significant inter- and intra-annual fluctuations in the spatial and temporal distribution of stock biomass, biological growth and recruitment. During its life cycle the population annually migrates between Norwegian, Russian and international waters. Moreover, while the mature stock migrates towards the Norwegian coast for spawning Russian waters observe a higher frequency of immature cod (Armstrong et al. 2014). The harvesting follows a strict seasonal pattern, where the main season takes place during the first quarter of the year (Eide et al. 2013). While the Russian share is harvested entirely with ocean-going vessels, i.e. trawlers, the Norwegian fleet consist of both trawlers and conventional fishing gear, i.e. the coastal fleet. Figure 1 illustrates how recent catches (20052013) are distributed between the two nations, and between the Norwegian trawler and coastal fleets, whereas Figure 2 exhibits how the total harvest is allocated between immature and mature fish. See Eide et al. (2013) and Armstrong et al. (2014) for a thorough description of this fishery with its related management institutions.

\section{FIGURE 1 ABOUT HERE}

While the catch of immature cod has been reasonable stable over the last decade, the amount of mature cod caught has been fluctuating. These fluctuations are mainly due to varying recruitments and fishing induced changes in the age-composition of the stock. In addition to the choice of gear, an obvious distinction between the trawlers and the coastal fleet is the area of harvesting; only under certain conditions are trawlers allowed to fish within the zone of 12 nautical miles, and never within that of 6 nautical miles

(https://lovdata.no/dokument/SF/forskrift/2004-12-22-1878/KAPITTEL_14\#KAPITTEL_14). As a result, the two fleets target cod constituting different age compositions. While the high sea trawler fleet's harvest consists of smaller and to some extent immature fish, the coastal fleet targets larger mature fish. The main season for both fleets is during the cod spawning season.

\section{FIGURE 2 ABOUT HERE}

Figure 3 illustrates the fairly fixed maturation process which the individual cod exhibits, and according to the International Council for the Exploration of the Sea (Anon. 2013), NEA cod 
may be regarded as immature when between the age of 3- and 6 years old. The minimum size of legal catches is $44 \mathrm{~cm}$, a size that enables the legal harvest of almost the entire class of immature fish between four and six years.

\section{FIGURE 3 ABOUT HERE}

The cannibalistic behaviour of the NEA cod stock is well known. Bogstad et al. (1994) argue that the frequency of cannibalism in the NEA cod stock declined in the late 1970s, reaching a point where cannibalism contributed to less than $1 \%$ of the cod's food consumption.

According to Yaragina et al. (2009) cannibalism in the 1990s increased to a level comparable with the 1950s. Both studies find cannibalism to be strongly correlated with the abundance of young immature cod. On the other hand, there is more controversy concerning the correlation between cannibalism and the availability of the cod's main source of prey, namely capelin (Bogstad et al. 1994; Yaragina et al. 2009). Wikan and Eide (2004) discuss cod cannibalism within the framework of a nonlinear stage-structured model and conclude that while increasing fecundity has a destabilising effect, cannibalism imposes a stabilising element in the growth dynamics of the cod stock. Additionally, cannibalism appears to be a significant source of mortality for young cod, and an important factor in explaining the rather weak functional relationship between spawning biomass and recruitment measured at the age of three years (Yaragina et al. 2009). Cannibalism is taken into account in our analysis by utilization of a peak-valued recruitment function (section three below).

\section{Biological model}

Our harvesting model utilises a generic biological model including three stages of the population's life cycle. These three stages at time (year) $t$ are recruits $X_{1, t}$ (year $<1$ ), immature fish $X_{2, t}(1 \leq$ year $<6)$ and mature fish $X_{3, t}(6 \leq$ year $)$ which contributes to spawning. While the two latter stages are targeted in the fishery, recruits are not part of the fishable stock ${ }^{1}$. Recruitment is endogenous and density dependent, while natural mortality is

\footnotetext{
${ }^{1}$ According to the Anon. (2013), a more realistic structure would be to categorise recruits as year $<3$. However, this would have complicated the modelling significantly without adding very much new insights. Therefore, with our model assumption the fish remains as recruits for only one year.
} 
assumed to be constant and stock independent for all three stages. In the single period of one year, three events happen in the following order; first spawning and recruitment, then fishing and finally natural mortality ${ }^{2}$.

The number of recruits is first governed by the recruitment function:

$$
X_{1, t}=R\left(X_{3, t}\right)
$$

assumed to be of the peak-valued Shepherd type (see numerical section seven for specification). The recruitment function is characterised by $R(0)=0, d R / d X_{3, t}=R^{\prime}>0$ for a small and medium sized spawning population, and $R^{\prime}<0$ when the spawning stock becomes so large that cannibalism dominates. The number of immature fish follows next as:

$$
X_{2, t+1}=s_{12} X_{1, t}+s_{22}\left(1-f_{2, t}\right) X_{2, t}
$$

where $s_{12}$ denotes the proportion of the recruits that survive the one-year time period $(t, t+1)$, and moves into the next stage class, i.e. the immature fish class, at the beginning of period $t+1 . s_{22}$ denotes the proportion of already immature that survive and stays one more year within this stage class. Therefore, while $s_{12}$ indicates the proportion of the recruits that moves into the immature stage, $s_{22}$ represents the proportion of immature fish that remain in this stage one more year. This equation thus differs from the age model equivalent where the parameters would represent pure survival rates as everyone surviving would move on to the next age class. See the Appendix for more details. $0 \leq f_{2, t} \leq 1$ defines total fishing mortality of immature fish. Finally, the number of mature fish is described by:

$$
X_{3, t+1}=s_{23}\left(1-f_{2, t}\right) X_{2, t}+s_{33}\left(1-f_{3, t}\right) X_{3, t}
$$

Here $s_{33}$ is a pure survival rate whereas $s_{23}$ also express transition from the previous stage. Moreover, it follows that $s_{22}+s_{23}$ is the pure survival rate for immature fish as the

\footnotetext{
${ }^{2}$ A more real life approach would be to let natural - and fishing mortality occur simultaneously throughout the year, as modelled by Beverton and Holt (1957). However, the simplifying assumption made here should not be detrimental to the model (see e.g. Skonhoft et al. 2012).
} 
transitions are cancelled out. $0 \leq f_{3, t} \leq 1$ is total fishing mortality for the mature stock. Notice also that Eqs. (2) and (4) differ from the age model equivalent as fishing of the young fish, here considered as immature fish, would have been omitted in Eq. (2). Eq. (3), which describe the relationship between the immature age class and the mature age class is notified as the spawning constraint. Eqs. (1) and (2) can be combined to express the recruitment constraint:

$$
X_{2, t+1}=s_{12} R\left(X_{3, t}\right)+s_{22}\left(1-f_{2, t}\right) X_{2, t} .
$$

Therefore, Eqs. (3) and (4) represent a reduced form model in two stage-classes, where both equations are first order difference equations ${ }^{3}$.

With fixed fishing mortalities, the population equilibrium is defined by $X_{i, t+1}=X_{i, t}=X_{i}$ ( $i=2,3$ ) such that:

$$
X_{3}=s_{23}\left(1-f_{2}\right) X_{2}+s_{33}\left(1-f_{3}\right) X_{3}
$$

and

$$
X_{2}=s_{12} R\left(X_{3}\right)+s_{22}\left(1-f_{2}\right) X_{2}
$$

Note that an internal equilibrium only holds for $0 \leq f_{2}<1$; that is, in order to sustain a mature spawning stock, the entire immature stock cannot be harvested. With a Shepherd (or Ricker) type recruitment function, the recruitment constraint (4') is depicted as in Figure 4. A higher fishing mortality of mature fish shifts up the spawning constraint (3') in the $X_{3}-X_{2}$ plane and hence leads to smaller fish stocks if recruitment initially is below its peak value. Higher fishing mortality of the immature fish $f_{2}$ also shift the spawning constraint (3') up, but in addition it shifts the recruitment constraint (4') down. In this situation, more aggressive fishing also leads to lower fish stocks if recruitment initially is below its peak value.

\footnotetext{
${ }^{3}$ It can easily be shown that this is a (locally) stable system for fixed harvesting rates as Eq. (3') intersects with Eq. (4') from below. See Figure 1.
} 
However, somewhat surprisingly, it works in the direction of increasing the equilibrium proportion of the immature fish. In a harvest program with $0<f_{3}<1$ and $f_{2}=0$, the equilibrium stock composition simply reads $X_{2} / X_{3}=\left[1-s_{33}\left(1-f_{3}\right)\right] / s_{23}$.

\section{FIGURE 4 ABOUT HERE}

\section{Fishing mortalities and bycatch}

As indicated, we assume the stock is targeted by two fishing fleets utilizing different gear. While the trawler fleet is targeting the immature fish, the coastal fleet, using conventional gear, is targeting the mature fish at the spawning grounds along the coast of northern Norway. To a certain extent, the fleets might be able to influence the relative amount of bycatch by technical measures or spatial distribution of fishing activities (see, e.g., Beverton and Holt 1957 and Clark 1990, and the more recent Singh and Weninger 2009). Moreover, by design, bycatch will be less of a problem in a stage structured model as opposed to an age structured one because the definition of stages introduces a less strict, though somewhat more realistic, picture of selectivity. Irrespective of this however, not seldom the catch is composed of species from different stage classes and hence there is 'bycatch'4 . Fishing mortalities are assumed to be governed by the Baranov-type catch function, thus indicating that the fishing mortalities in our model always will be below one ${ }^{5}$. While the intended fishing mortality rate is denoted by $h_{i, t}(i=1,2)$, the bycatch of one stage class is assumed to be proportional to the intended harvest of the other stage class. Accordingly:

$$
f_{2, t}=h_{2, t}+\alpha_{2} h_{3, t}
$$

\footnotetext{
${ }^{4}$ FAO defines bycatch as: 'Bycatch will be used to refer to that part of the catch which is not primary target of the fishing effort. It consists of both fish which is retained and marketed (incidental catch) and that which is discarded or released' (Clucas 1997). In the present model, all bycatch is assumed to be retained and marketed.

${ }^{5}$ Applying a Baranov catch function the coastal fleet's intended catch of mature fish is formulated as $H_{3, t}=$ $X_{3, t}\left(1-e^{-q_{3} E_{3, t}}\right)$. The coastal fleet's bycatch of immatures is correspondingly $B_{2, t}=X_{2, t}\left(1-e^{-\widetilde{q_{2}} E_{3, t}}\right) . E_{3, t}$ is effort of the coastal fleet, while $q_{3}$ and $\widetilde{q_{2}}$ are the coastal fleet's catchability coefficients for the target catch of matures and the bycatch of immatures, respectively. With the similar structure for the trawlers, total fishing mortality of matures may be written as $f_{3, t}=H_{3, t} / X_{3, t}+\left(\left(B_{3, t} / X_{3, t}\right) /\left(H_{2, t} / X_{2, t}\right)\right)\left(H_{2, t} / X_{2, t}\right)$, in which $\left(B_{3, t} / X_{3, t}\right) /\left(H_{2, t} / X_{2, t}\right)$ is $\alpha_{3}$, and indicates that $\alpha_{3} \leq 1$ holds when $q_{2} \leq \widetilde{q_{3}}$. Finally it follows that $f_{3, t}=$ $\left(1-e^{-q_{3} E_{3}}\right)+\left(1-e^{-\widetilde{q_{3} E_{2}}}\right)$, and likewise for the total mortality of immatures.
} 
describes total fishing mortality rate of the immature cod stock. Therefore, while $h_{2, t}$ is the fishing mortality caused by the trawler fleet, the coastal fleet's bycatch of immature fish is defined as a constant proportion, $\alpha_{2} \geq 0$, of their intended catch of mature fish, $h_{3, t}$. Correspondingly,

$$
f_{3, t}=h_{3, t}+\alpha_{3} h_{2, t}
$$

describes total fishing mortality rate of the mature stock with $\alpha_{3} h_{2, t}\left(\alpha_{3} \geq 0\right)$ as the trawler fleet's bycatch of mature fish. Intuitively, one may think the restriction $\alpha_{i} \leq 1,(i=2,3)$ should hold. For the coastal fleet this implies that it has a higher catchability coefficient for mature fish than for immature fish. For the trawler fleet targeting the immature fish stock the opposite will hold. Moreover, it may be reasonable to assume that the coastal fleet has a finer degree of selectivity than the trawler fleer, i.e. $\alpha_{2}<\alpha_{3}$ (Diekert et al., 2010b).

In addition to targeting cod both fleets also harvest saithe and haddock and there are arrangements for additional bycatch of these species. While there are cases of Greenland shark being taken as bycatch by trawlers and some of the larger coastal vessels, the bycatch of species outside the target group does not seem to be a major problem (https://www.fiskeridir.no/Yrkesfiske/Regelverk-og-reguleringer/J-meldinger/Utgaatte-Jmeldinger/J-54-2017, http://www.imr.no/tokt/toktomtaler/si_arktis/toktdagbok_2015/pa_jakt_etter_en_arktisk_kjem pefisk/en). Due to the high mortality of discards the discarding of fish is illegal, and both fleets are in general subject to the same level of monitoring and enforcement. Any other gear contact externalities are assumed to be similar for the two fleets.

\section{Maximum yield fishing with perfect fishing selectivity}

\subsection{Optimality conditions}

First, we study the maximum biomass yield (MY) problem with perfect fishing selectivity; that is, $\alpha_{i}=0$, such that $f_{i, t}=h_{i, t}(i=2,3)$ from Eqs. (5) and (6). With $w_{2}$ and $w_{3}$ as fixed (average) weight $(\mathrm{kg} / \mathrm{fish})$ of respectively immature and mature fish, and where $w_{3}>w_{2}$, the current harvested biomass (kg) reads $Y_{t}=w_{2} h_{2, t} X_{2, t}+w_{3} h_{3, t} X_{3, t}$. The maximum biomass yield 
problem is then defined by $\max _{0 \leq h_{2, t}<1,0 \leq h_{3, t}<1} \sum_{t=0}^{\infty} \rho^{t} Y_{t}$, subject to the spawning - and recruitment constraints Eqs. (4) and (3), respectively. Additionally, initial stock sizes $X_{i, 0}$ ( $i=2,3$ ) have to be known. $\rho=1 /(1+\delta) \leq 1$ is the discount factor with $\delta \geq 0$ as the discount rate. The Lagrangian is formulated as

$$
\begin{gathered}
L=\sum_{t=0}^{\infty} \rho^{t}\left\{\left(w_{2} h_{2, t} X_{2, t}+w_{3} h_{3, t} X_{3, t}\right)-\rho \lambda_{t+1}\left[X_{2, t+1}-s_{12} R\left(X_{3, t}\right)-s_{22}\left(1-h_{2, t}\right) X_{2, t}\right]\right. \\
\left.-\rho \mu_{t+1}\left[X_{3, t+1}-s_{23}\left(1-h_{2, t}\right) X_{2, t}-s_{33}\left(1-h_{3, t}\right) X_{3, t}\right]\right\}
\end{gathered}
$$

with $\lambda_{t}>0$ and $\mu_{t}>0$ as the shadow values (kg/fish) of imature and mature fish, repectively. Following the Kuhn -Tucker theorem, the first order necessary conditions (assuming $X_{i}>0$, $i=2,3)$ are:

$$
\left(\partial L / \partial h_{3, t}\right) / \rho^{t}=X_{3, t}\left(w_{3}-\rho \mu_{t+1} s_{33}\right) \leq 0 ; 0 \leq h_{3, t}<\quad 1, t=0,1,2, \ldots,
$$

$$
\left(\partial L / \partial X_{2, t}\right) / \rho^{t}=w_{2} h_{2, t}-\lambda_{t}+\rho \lambda_{t+1} s_{22}\left(1-h_{2, t}\right)+\rho \mu_{t+1} s_{23}\left(1-h_{2, t}\right)=0, \quad t=1,2,3, \ldots
$$

and

$$
\left(\partial L / \partial X_{3, t}\right) / \rho^{t}=w_{3} h_{3, t}+\rho \lambda_{t+1} s_{12} R^{\prime}\left(X_{3, t}\right)-\mu_{t}+\rho \mu_{t+1} s_{33}\left(1-h_{3, t}\right)=0, t=
$$

$1,2,3 \ldots$.

The interpretation of the control conditions (7) and (8) are straightforward as they express simple marginal gain - loss relationships. Condition (7) states that the immature stock should be harvested until the marginal biomass gain of harvesting is less than or equal to the economically ( $\rho$ ) discounted marginal biomass loss, evaluated at the biological ( $s_{22}$ and $s_{23}$ ) discounted shadow prices. In other words, harvesting should continue until the value of the 
last fish harvested is equal to the value of leaving that fish in the ocean. From the control conditions it also follows that, ceteris paribus, an increase in discounting reduce the marginal cost of harvesting and will thus lead to more aggressive harvesting. The same is also true for natural mortality, and the transition and survival parameters. Control condition (8) is analogous for the mature stock. Eqs. (9) and (10) are the portfolio, or stock, conditions which steer the shadow price values. Rearranging Eq. (9) as $\lambda_{t}=w_{2} h_{2, t}+\rho \lambda_{t+1} s_{22}\left(1-h_{2, t}\right)+\rho \mu_{t+1} s_{23}\left(1-h_{2, t}\right)$, it is evident that the number of immature fish should be maintained such that its shadow price equalizes its marginal biomass gain value plus the marginal biomass loss, evaluated at the biological discounted shadow prices. Stock condition (10) can be given a similar interpretation, but here there is also a direct effect of recruitment. A sufficient condition for optimality is that the Lagrangian should be jointly concave in the control and state variables. While this is difficult to prove, it should generally hold as long as the recruitment function is concave.

Assuming it is optimal to only harvest the mature fish, condition (7) will hold as an inequality while condition (8) will hold as an equation. This leads to the condition $w_{3} / s_{33}>\left(w_{2}-\right.$ $\left.\rho \lambda_{t+1} s_{22}\right) / s_{23}$. Quite naturally, the average weight of the mature fish exceeds that of immature fish, $w_{3}>w_{2}$. Due to the stage structure of our model, we also have $s_{33}>s_{23}$. This contrasts with an age structured model where both parameters would be pure survival rates with little to no difference between them (again, see the Appendix for further discussion). With the baseline data we thus find $w_{3} / s_{33}<w_{2} / s_{23}$, and hence the shadow value of the immature stock is crucial when determining which stage class to harvest. In section 7.2, however, we can conclude that $w_{3} / s_{33}>\left(w_{2}-\rho \lambda_{t+1} s_{22}\right) / s_{23}$ is fulfilled with the baseline parameter values. More specifically, the condition thus states that it is optimal to only harvest the mature stock, here utilized by the conventional fleet, when the marginal biomass gain of harvesting matures is greater than the marginal biomass gain of harvesting immatures, both adjusted for the probability of surviving until the next year. Additionally, the economic and biological discounted shadow price of not letting the immature individual grow for another period, adjusted for the probability that the individual will survive and transfer to the mature stage class, also has to be taken into account. Accordingly, when this inequality holds the trawler fleet should not fish at all; that is, $1>h_{3, t}>h_{2, t}=0$. In other words, under this assumption, exploiting the mature stock while leaving the immature stock unexploited will maximize the biomass yield. This is stated as: 
Result 1: In our stage structured model with perfect fishing selectivity and where the biomass yield is maximized, it is optimal to only harvest the old and more valuable stage class.

This result is in line with Reed (1980) and Skonhoft et al. (2012) which considered age structured models, but the result is more clear-cut in these age structured models because only pure survival rates are included. Notice also that the simple structure of our result is to some extent contingent upon the Baranov catch function where the total fishing mortalities are restricted from reaching one. With a Schaefer catch function and the possibility of fishing mortalities equal to one, there would be a set of different cases to consider. Nevertheless, harvest of the mature age class should still be prioritized with this harvesting technology. See Skonhoft et al. (2012) for an analysis and discussion.

\subsection{Transitional dynamics}

As the yield function is linear in the controls, economic theory suggests that fishing should be adjusted to lead the fish stocks to steady state as fast as possible; that is, Most Rapid Approach Path (MRAP) dynamics. However, the MRAP is not a regular one in our stagestructured fish population because, among others, the steady state will be a corner solution with zero fishing of the immature stock. The stage structure implies that the population could be above that of the optimal steady state level for one stage class and at the same time lower than the optimal steady state level for the other stage class. Since fishing is confined to two stage classes, the MRAP may imply a large harvest in one period and small, or zero, harvest in the next.

The harvest of the two stage-classes also needs to be considered jointly before the optimal steady state is achieved, because the population of both immature and mature fish affects the optimal harvest rate of the other stage class through its impact on the size of the spawning population. In our case with $w_{3} / s_{33}>\left(w_{2}-\rho \lambda_{t+1} s_{22}\right) / s_{23}$ and only harvesting the mature stock, the proportion of the mature fish to be harvested will depend on the number of immature fish. If the number of fish in this stage is small, it may be necessary to reduce the harvest of the mature fish to obtain the desirable size of the spawning stock. On the contrary, if the number of immature fish is large, it may be necessary to harvest all or some of the mature fish even if the number of fish of the stage class is lower than the optimal steady state. In our numerical illustration (section seven below), we find with our baseline parameter 
values and initial stock conditions that the harvest rate of the mature stock should gradually increase over time until steady state is approached.

\subsection{Steady state analysis and MSY}

In a steady state with constant harvest and stock sizes over time, the above first order conditions (7) - (10) with $1>h_{3}>h_{2}=0$ reads:

$$
X_{2}\left(w_{2}-\rho \lambda s_{22}-\rho \mu s_{23}\right)<0 ; h_{2}=0,
$$

and

$$
X_{3}\left(w_{3}-\rho \mu s_{33}\right)=0 ; 0<h_{3}<1,
$$

$$
\lambda=\rho \lambda s_{22}+\rho \mu s_{23}
$$

From Eq. (8'), the spawning constraint shadow price is $\mu^{*}=w_{3} / \rho s_{33}$ (superscript '*' indicates optimal steady state values) while the recruitment constraint shadow price follows next from Eq. (9') as $\lambda^{*}=s_{23} w_{3} /\left(1-\rho s_{22}\right) s_{33}$. According to these shadow values (kg/fish), the immature stock is more valuable (in the ocean) than the mature stock if $\lambda^{*}-\mu^{*}=\left(w_{3} / s_{33}\right)\left[s_{23} /\left(1-\rho s_{22}\right)-(1 / \rho)\right]>0$, or $\left(s_{22}+s_{23}\right)>1 / \rho=(1+\delta)$. However, somewhat surprisingly, this does not hold with our baseline parameter values. The main reason is that the survival rates do not represent pure survival rates in the stage model. These shadow price values can be inserted into Eq. (10') to find the slope of the recruitment function, $R^{\prime}\left(X_{3}\right)=\frac{\left(1-\rho s_{22}\right)\left(1-\rho s_{33}\right)}{\rho^{2} s_{23} s_{12}}>0$. Concurrently, the optimal steady state mature fish stock $X_{3}^{*}$ will always be below the peak value of the recruitment function. This implies that it is beneficial to restrict the size of the mature stock in order to curb cannibalism and omit negative marginal recruitment growth (see Figure 1). Intuitively, recruits taken by cannibalism represent lost yield for the fishermen, and thus yield/stock loss through 
cannibalism should be minimized, pushing towards a smaller stock size of matures. This is stated as:

Result 2: With a peak-valued recruitment and perfect fishing selectivity, the optimal steady state harvesting policy implies that the mature stock should be harvested such that recruitment growth always is positive.

To some extent, Result 2 relies on the stage structure of our model where all mature age classes is collected into one single stage of mature fish such that only one harvestable class contributes to recruitment. When the size of the mature stock is determined, the immature stock size $X_{2}^{*}$ is defined through the recruitment constraint (4') which becomes $X_{2}=$ $s_{12} R\left(X_{3}\right)+s_{22} X_{2}$ when $h_{2}^{*}=0$. The spawning constraint (3'), here as $X_{3}=s_{23} X_{2}+s_{33}\left(1-h_{3}\right) X_{3}$, finally determines optimal fishing mortality of the mature stock, $0<h_{3}^{*}<1$. This condition implies that the immature - mature stock ratio must be within the range $\left(1-s_{33}\right) / s_{23}<X_{2}^{*} / X_{3}^{*}<1 / s_{23}$. When inserting for the survival and transition parameters (see numerical illustration for parameter values) this ratio is confirmed as above one, and hence the steady state stock of immature fish, consisting of several age classes, will exceed that of mature fish irrespective of the size of the fishing mortality of the mature stock, also consisting of several age classes.

The steady state comparative statics are presented in Table 1 . As most of the effects are channelled through the expression for $R^{\prime}\left(X_{3}\right)$ the valuation of the fish stocks, i.e., $w_{2}$ and $w_{3}$, have no impact on optimal stock sizes, nor on optimal level of fishing activity, i.e. $\partial h_{3}^{*} / \partial w_{i}=0(i=2,3)$. This is stated as:

Result 3: The valuation of the fish stocks has no impact on the level of exploitation.

While this result may be surprising, it is to some extent a result of the problem design where only one of the harvestable stage classes contribute to recruitment, and where it is the number of individuals, and not the size of the biomass that determines spawning, recruitment and 
potential cannibalism ${ }^{6}$. In addition, we may recall that the weight difference, $w_{3}>w_{2}$, already has been included to determine which stage class to harvest.

As expected, the higher the discount rate, $\delta$, the greater the slope of the recruitment function $R^{\prime}\left(X_{3}\right)$. Concurrently, the manager will find it beneficial to keep less of the mature stock $X_{3}^{*}$; that is, $\partial X_{3}^{*} / \partial \delta<0$. At the same time, the size of the immature stock $X_{2}^{*}$ reduces while fishing mortality $h_{3}{ }^{*}$ increases to restore equilibrium. More aggressive fishing and lower standing biomass as a result of a more myopic policy are in line with the standard fishery model (the 'Clark model'; Clark 1990), but here this effect is present simultaneously for two fractions of the stock. Higher survival rates, which increase all of the combined survival and transition parameters in our stage structured model, work in the opposite direction and hence indicate less aggressive harvesting and higher fish density. Moreover, while fertility and the fertility parameters have no direct impact upon the harvesting decision through the control conditions, these parameters will definitively influence the exploitation pressure and the fish abundance as they affect the slope of $R^{\prime}\left(X_{3}\right)$. For example, we find that a higher value of the parameter indicating maximum recruitment increases $X_{3}^{*}$. For details, see the numerical illustration.

Table 1 also includes the effects on optimal yield, $Y^{*}=w_{3} h_{3}^{*} X_{3}^{*}$, which unambiguously increases with a more valuable mature stock as both stock and harvest rate are unaffected, $\partial Y^{*} / \partial w_{3}=h_{3}^{*} X_{3}^{*}$. On the other hand, $\partial Y^{*} / \partial w_{2}=0$ as the immatures are left unexploited. The optimal size of the standing biomass, $B^{*}=w_{2} X_{2}^{*}+w_{3} X_{3}^{*}$, is influenced by the stock value with $\partial B^{*} / \partial w_{3}=X_{3}^{*}$ and $\partial B^{*} / \partial w_{2}=X_{2}^{*}$. The discount rate affect yield through the optimal stock size as well as optimal fishing mortality. However, these effects work in opposite directions and the sign of $\left.\partial Y^{*} / \partial \delta=w_{3}\left[\partial h_{3}^{*} / \partial \delta\right) X_{3}^{*}+\left(\partial X_{3}^{*} / \partial \delta\right) h_{3}^{*}\right]$ is ambiguous. The expected relationship is certainly negative, i.e. $\partial Y^{*} / \partial \delta<0$, and this is confirmed numerically. As expected, we also find $\partial B^{*} / \partial \delta<0$ as both stocks are reduced in response to a more myopic harvesting policy.

\footnotetext{
${ }^{6}$ Consider the case with a biomass determined recruitment, then the slope of the recruitment function would be $R^{\prime}\left(w_{3} X_{3}\right)$, which is constant and determined by the survival rates and discount factor (main text above). Consequently, any change in $w_{3}$ must be balanced by an equivalent change in $X_{3}$ to restore the steady state.
} 


\section{TABLE 1 ABOUT HERE}

With $\rho=1$, or $\delta=0$, and where the steady state hence describes a Maximum Sustainable Yield (MSY) fishery (section one above), we find as indicated above that $R^{\prime}\left(X_{3}^{m s y}\right)=$ $\frac{\left(1-s_{22}\right)\left(1-s_{33}\right)}{s_{23} s_{12}}<R^{\prime}\left(X_{3}^{*}\right)$. Therefore, we also have higher stock sizes, $X_{3}^{m s y}>X_{3}^{*}$ and $X_{2}^{m s y}>X_{2}^{*}$. Accordingly, $h_{3}^{m s y}<h_{3}^{*}$ will hold. We may also expect $Y^{m s y}=w_{3} h_{3}^{m s y} X_{3}^{m s y}>Y^{*}=w_{3} h_{3}^{*} X_{3}^{*}$, but this is as indicated difficult to prove. Nevertheless, the MSY standing biomass will certainly exceed that of the optimal steady state standing biomass, $B^{m s y}=w_{3} X_{3}^{m s y}>B^{*}=w_{3} X_{3}^{*}$.

\section{Maximum yield fishing with imperfect fishing selectivity}

As indicated, bycatch will be less of a problem in a stage structured model as opposed to an age structured one. However, including bycatch can still be considered as the more realistic scenario, and thus we now proceed to study the case of imperfect selectivity, i.e., $\alpha_{2}>0$ and $\alpha_{3}>0$. With Eqs. (5) and (6) and bycatch the biological constraints (3) and (4) read:

$$
X_{3+1, t}=s_{23}\left(1-h_{2, t}-\alpha_{2} h_{3, t}\right) X_{2, t}+s_{33}\left(1-h_{3, t}-\alpha_{3} h_{2, t}\right) X_{3, t}
$$

and

$$
X_{2, t+1}=s_{12} R\left(X_{3, t}\right)+s_{22}\left(1-h_{2, t}-\alpha_{2} h_{3, t}\right) X_{2, t},
$$

respectively. Though no longer assured by the Baranov production functions, we assume the fishing mortalities remain below one such that $0 \leq h_{2, t}+\alpha_{2} h_{3, t}<1$ and $0 \leq h_{3, t}+$ $\alpha_{3} h_{2, t}<1$. If it remains optimal to only utilize one fleet this will definitely hold. When the sharing rule is introduced in section 8 , the condition is somewhat dependent on the proportion of bycatch, though the numerical illustrations indicate that it holds. The Lagrangian of the maximum yield problem now reads

$$
\begin{aligned}
& L=\sum_{t=0}^{\infty} \rho^{t}\left\{\left(w_{2} X_{2, t}\left(h_{2, t}+\alpha_{2} h_{3, t}\right)+w_{3} X_{3, t}\left(h_{3, t}+\alpha_{3} h_{2, t}\right)\right)-\rho \lambda_{t+1}\left[X_{2, t+1}-\right.\right. \\
& \left.s_{12} R\left(X_{3, t}\right)-s_{22}\left(1-h_{2, t}-\alpha_{2} h_{3, t}\right) X_{2, t}\right]-\rho \mu_{t+1}\left[X_{3, t+1}-s_{23}\left(1-h_{2, t}-\alpha_{2} h_{3, t}\right) X_{2, t}-\right. \\
& \left.\left.s_{33}\left(1-h_{3, t}-\alpha_{3} h_{2, t}\right) X_{3, t}\right]\right\} .
\end{aligned}
$$


The first order conditions with $X_{i}>0(i=2,3)$ are:

$$
\left(\partial L / \partial h_{2, t}\right) / \rho^{t}=X_{2, t}\left(w_{2}-\rho \lambda_{t+1} s_{22}-\rho \mu_{t+1} s_{23}\right)+X_{3, t}\left(w_{3}-\rho \mu_{t+1} s_{33}\right) \alpha_{3} \leq
$$

$0 ; 0 \leq h_{2, t}<1, t=0,1,2, \ldots$,

$$
\left(\partial L / \partial h_{3, t}\right) / \rho^{t}=X_{3, t}\left(w_{3}-\rho \mu_{t+1} s_{33}\right)+X_{2, t}\left(w_{2}-\rho \lambda_{t+1} s_{22}-\rho \mu_{t+1} s_{23}\right) \alpha_{2} \leq
$$

$0 ; 0 \leq h_{3, t}<1, t=0,1,2, \ldots$,

$$
\left(\partial L / \partial X_{2, t}\right) / \rho^{t}=w_{2}\left(h_{2, t}+\alpha_{2} h_{3, t}\right)-\lambda_{t}+\rho \lambda_{t+1} s_{22}\left(1-h_{2, t}-\alpha_{2} h_{3, t}\right)+
$$

$\rho \mu_{t+1} s_{23}\left(1-h_{2, t}-\alpha_{2} h_{3, t}\right)=0, t=1,2,3, \ldots$

and

$$
\left(\partial L / \partial X_{3, t}\right) / \rho^{t}=w_{3}\left(h_{3, t}+\alpha_{3} h_{2, t}\right)+\rho \lambda_{t+1} s_{12} R^{\prime}\left(X_{3, t}\right)-\mu_{t}+\rho \mu_{t+1} s_{33}\left(1-h_{3, t}-\right.
$$
$\left.\alpha_{3} h_{2, t}\right)=0, t=1,2,3 \ldots$.

We assume $w_{3} / s_{33}-\rho \mu_{t+1}>0$ and $w_{2} / s_{23}-\rho \lambda_{t+1} s_{22} / s_{23}-\rho \mu_{t+1}<0$. Combined, these yield $w_{3} / s_{33}>w_{2} / s_{23}-\rho \lambda_{t+1} s_{22} / s_{23}$, which exactly corresponds to the perfect selectivity condition for the sole harvest of matures (section 5.1 above). Further assume that, in spite of imperfect selectivity, it is still optimal to only use the coastal fleet such that condition (13) holds as an inequality while condition (14) holds as an equation, i.e., $1>h_{3, t}>h_{2, t}=0$. Thus, from Eq. (14) $X_{2, t}\left(w_{2}-\rho \lambda_{t+1} s_{22}-\rho \mu_{t+1} s_{23}\right)=-X_{3, t}\left(w_{3}-\rho \mu_{t+1} s_{33}\right) / \alpha_{2}$, and together with Eq. (13) we have that $-X_{3, t}\left(w_{3}-\rho \mu_{t+1} s_{33}\right) / \alpha_{2}+X_{3, t}\left(w_{3}-\rho \mu_{t+1} s_{33}\right) \alpha_{3}<0$. This last inequality implies $-1 / \alpha_{2}+\alpha_{3}<0$, or $\alpha_{2} \alpha_{3}<1$. Given that $w_{3} / s_{33}>w_{2} / s_{23}-\rho \lambda_{t+1} s_{22} / s_{23}$ holds, we hence find that $0<h_{3, t}<1$ and $h_{2, t}=0$ is consistent with $\alpha_{2} \alpha_{3}<1$. Therefore, with $\alpha_{2} \alpha_{3}<1$ as a restriction on the degree of bycatch, it remains optimal to only use the costal fleet, targeting the mature fish, to exploit the fish population. This is stated as:

Result 4: With bycatch, but restricted degree of bycatch and $\alpha_{2} \alpha_{3}<1$, it is still optimal to utilize only the coastal fleet. 
We may have, $\alpha_{3}>1$ and 'high' bycatch of mature fish by the trawler fleet. However, as long as this is counterbalanced by a 'small' amount of bycatch of immature fish by the coastal fleet with $\alpha_{2}$ well below one, the present bycatch restriction will hold. Applying only the coastal fleet may also be present with the opposite bycatch situation; that is, with $\alpha_{2}$ 'high' and $\alpha_{3}$ 'low'. Notice also that the above result prevails when bycatch by one of the fleets equalizes zero. Therefore, it is the combined degree of bycatch that matters, and not each fleets' individual level of bycatch. While this may seem surprising at first, intuitively, the combined degree of bycatch tells us which fleet is the most efficient at catching mature fish. This will be the fleet with the smallest proportion of immature fish in their total harvest, seeing as harvesting immatures is a cost to society as long as immature fish are more valuable when left in the ocean, than when harvested. Nevertheless, as shown in the numerical illustrations, the level of bycatch still affects the optimal level of harvesting.

Suppose instead that it is optimal to utilize the trawler fleet and target the immature stock such that $1>h_{2, t}>h_{3, t}=0$ holds irrespective of the fact that we still assume $w_{3} / s_{33}>w_{2} / s_{23}-\rho \lambda_{t+1} s_{22} / s_{23}$. Control condition (13) is then an equation and may be written as $X_{2, t}\left(w_{2}-\rho \lambda_{t+1} s_{22}-\rho \mu_{t+1} s_{23}\right)=-X_{3, t}\left(w_{3}-\rho \mu_{t+1} s_{33}\right) \alpha_{3}$. Combined with control condition (14) as an inequality written as $X_{2, t}\left(w_{2}-\rho \lambda_{t+1} s_{22}-\rho \mu_{t+1} s_{23}\right) \alpha_{2}<$ $-X_{3, t}\left(w_{3}-\rho \mu_{t+1} s_{33}\right)$, yields $-X_{3, t}\left(w_{3}-\rho \mu_{t+1} s_{33}\right) \alpha_{3}<-X_{3, t}\left(w_{3}-\rho \mu_{t+1} s_{33}\right) / \alpha_{2}$. This implies the bycatch restriction $-\alpha_{3}<-1 / \alpha_{2}$, or $\alpha_{2} \alpha_{3}>1$, and hence a 'high' degree of bycatch. Recall that with $\alpha_{i}>1$ the fishing mortality would be greater for the bycatch stock than for the target stock, indicating the gear's selectivity is better suited to target the bycatch stock. Thus, using the trawler fleet to target the immature cod stock combined with bycatch of mature fish will be optimal if the combined degree of bycatch is 'high'. That is, if the trawler bycatch coefficient $\alpha_{3}$ is 'high' while at the same time the coastal fleet bycatch coefficient $\alpha_{2}$ is not too 'low' it is still optimal to harvest the mature stock, though utilizing a different gear. This is stated as:

Result 5: In a situation with high proportion of bycatch by the trawler fleet and $\alpha_{2} \alpha_{3}>1$, it is still optimal to prioritize to harvest the mature stock. The optimal harvest is then reached by utilizing the trawler fleet. 
Thus, in a similar manner to Result 4, given the assumption that it is optimal to only harvest mature fish, it will also be optimal to utilize the fleet that achieves this in the most efficient manner.

The effect of imperfect selectivity upon the optimal degree of exploitation is analysed in steady state with zero discount rent, which entails that the steady state of our dynamic problem coincides with the MSY problem (see above). We begin with the scenario where it is optimal to only utilize the coastal fleet to harvest mature fish; i.e., $\alpha_{2} \alpha_{3}<1$. By maximizing $Y=w_{2} X_{2} \alpha_{2} h_{3}+w_{3} X_{3} h_{3}$ using a direct approach and omitting the shadow prices, we find that:

$$
\partial Y / \partial h_{3}=w_{2} \alpha_{2}\left(X_{2}+h_{3}\left(\partial X_{2} / \partial h_{3}\right)\right)+w_{3}\left(X_{3}+h_{3}\left(\partial X_{3} / \partial h_{3}\right)\right)=0 ; 0<h_{3}<1
$$

describes the optimal harvest policy. Together with Eqs. (11) and (12), inserted for $h_{2}=0$, Eq. (17) define the MSY biomass, $Y^{m s y}$. Because the trawler fleet does not harvest, $\alpha_{3}$ does not influence the conditions for optimum, and $\partial Y^{m s y} / \partial \alpha_{3}=0$. On the other hand, $\alpha_{2}$ affects optimal yield directly through the stock, as well as indirectly through the optimal harvest policy. Harvested biomass may thus be written as $Y^{m s y}=w_{2} X_{2}^{m s y}\left(\alpha_{2}, h_{3}\left(\alpha_{2}\right)\right) \alpha_{2} h_{3}\left(\alpha_{2}\right)+w_{3} X_{3}^{m s y}\left(\alpha_{2}, h_{3}\left(\alpha_{2}\right)\right) h_{3}\left(\alpha_{2}\right)$. Through differentiation and the application of the envelope theorem, we find that $\partial Y^{m s y} / \partial \alpha_{2}=w_{2} X_{2}^{m s y} h_{3}^{m s y}+$ $h_{3}^{m s y}\left[w_{2}\left(\partial X_{2}^{m s y} / \partial \alpha_{2}\right)+w_{3}\left(\partial X_{3}^{m s y} / \partial \alpha_{2}\right)\right]$. The first term $w_{2} X_{2}^{m s y} h_{3}^{m s y}$ is the yield effect, which is positive. The yield effect is, however, counterbalanced by the negative distortion effect $\left[w_{2}\left(\partial X_{2}^{m s y} / \partial \alpha_{2}\right)+w_{3}\left(\partial X_{3}^{m s y} / \partial \alpha_{2}\right)\right]$, in which higher harvesting pressure through increased bycatch shifts the spawning constraint up, while simultaneously shifting the recruitment constraint down, leads to smaller stock sizes. If the distortion effect is 'large' the presence of bycatch will reduce the yield compared to a situation without bycatch. In principle, we will also have the same counteracting forces present influencing the optimal yield $Y^{*}$. This is stated as:

Result 6: Bycatch may either increase or reduce the optimal yield $Y^{*}$ and the maximum sustainable yield $Y^{m s y}$. 
To some extent, this may contradict intuition as joint production in the presence of bycatch, compared to perfect selectivity, could be interpreted as the replacement of a single good production without any additional effort, i.e. the fishing fleet is able to harvest more with the same amount of effort. On the other hand, bycatch implies that a fixed proportion of unintended catch is landed for every ton of intended catch. This reduces the flexibility of targeting age classes separately and the possibility of controlling the fish stocks in an optimal way (for a related discussion, see Skonhoft et al. 2012). In the numerical illustrations, this second effect dominates. In a parallel manner, the MSY biomass may be written as $B^{m s y}=w_{2} X_{2}^{m s y}\left(\alpha_{2}, h_{3}\left(\alpha_{2}\right)\right)+w_{3} X_{3}^{m s y}\left(\alpha_{2}, h_{3}\left(\alpha_{2}\right)\right)$. Differentiation yields $\partial B^{m s y} / \partial \alpha_{2}=\left[w_{2}\left(\partial X_{2}^{m s y} / \partial \alpha_{2}\right)+w_{3}\left(\partial X_{3}^{m s y} / \partial \alpha_{2}\right)\right]$ $+\left[w_{2}\left(\partial X_{2}^{m s y} / \partial h_{3}\right)+w_{3}\left(\partial X_{3}^{m s y} / \partial h_{3}\right)\right]\left(\partial h_{3}^{m s y} / \partial \alpha_{2}\right)$. The first bracket term [.] is again the above mentioned negative distortion effect. The other bracket term $\left[w_{2}\left(\partial X_{2}^{m s y} / \partial h_{3}\right)+w_{3}\left(\partial X_{3}^{m s y} / \partial h_{3}\right)\right]$ is also negative while we have not been able to find the sign of $\partial h_{3}^{m s y} / \partial \alpha_{2}$. However, in the numerical analysis this effect is also negative, $\partial h_{3}^{m s y} / \partial \alpha_{2}<0$ , and the net effect $\partial B^{m s y} / \partial \alpha_{2}$ is negative as well. Hence, the distortion effect dominates.

In the scenario where $a_{2} \alpha_{3}>1$ and it is optimal to only utilize the trawler fleet, we also find that bycatch may either decrease or increase the maximum sustainable yield $Y^{m s y}$. Therefore, Result 6 prevail in this case as well. Moreover, because there is no harvest of the coastal fleet in this case, it is evident that the bycatch coefficient of the coastal fleet has no influence the optimality conditions and $\partial Y^{m s y} / \partial \alpha_{2}=0$.

\section{Numerical illustrations}

\subsection{Data and functional forms}

In order to capture the idea that recruits are subject to cannibalism by mature fish, and where the degree of cannibalism is density dependent, we apply the Shepherd recruitment function:

$$
R\left(X_{3, t}\right)=\frac{r X_{3, t}}{1+\left(\frac{X_{3, t}}{K}\right)^{\eta}}
$$


with $\eta>1$ such that it describes a domed curve. More specifically $\eta$ is the compensation parameter which exhibits the degree to which density-dependent effects compensate for changes in the stock size. $r$ is the slope parameter indicating maximum recruitment per spawning individual, and $K$ is the threshold spawning stock size, above which the densitydependent effects dominate density independent effects (King 1995). Therefore, while $r$ indicates the reproduction capability, $K$ is scaling the population. Particularly, recruitment will be at its maximum when the stock of the matures is $X_{3}^{\max }=K\left(\frac{1}{\eta-1}\right)^{\frac{1}{\eta}}$, at which point recruitment is $R\left(X_{3}^{\max }\right)=\frac{r K(\eta-1)}{\eta(\eta-1)^{\frac{1}{\eta}}}$. In line with the arguments of Shepherd (1982), we use $\eta=2.2$ as the baseline value to illustrate the domed functional form of the recruitment function. Based on Diekert (2013) and the average weight of the fish in the mature stage class, $K$ is set to 84 million individuals, whereas $r$ is adapted from Myers et al. (1997) ${ }^{7}$. The rest of the baseline parameter values are given in Table 2. The survival and transition parameters are calculated based on a natural mortality rate equal to 0.2 and the assumption that, each year, one fifth of the immatures transition to the mature stage class. Again, see the Appendix for a further discussion of these parameters. The weights, $w_{2}$ and $w_{3}$, are calculated as the weighted average of all harvestable age-classes in, respectively, the immature and mature stage class. Lastly, a discount rate of $5 \%$ is chosen, $\delta=0.05$.

\section{TABLE 2 ABOUT HERE}

\subsection{Perfect Selectivity}

MATLAB R2016a is used to solve the model for a period of 50 years, though we exclude the last ten years to portray an infinite time horizon. Figure 5 first illustrates the dynamics of the system with perfect selectivity, and as expected from Result 1 only the mature stage class should be harvested, and where the steady state level is $h_{3}^{*}=0.76$. The harvesting rate of matures gradually increase over time, and population settles at a steady state after an adjustment period of 10-15 years. The length and nature of this adjustment period depends on the initial stock which was set to 40 mill individuals for each stage class. Both stocks, with the exception of an initial small reduction of the mature stock, also increase over time. This is parallel to the saddle point solution of the classical biomass fishery model

\footnotetext{
${ }^{7}$ Number of recruits per spawner in Myers et al. (1997) is adjusted for the fact that not all individuals in the mature stage class are in fact mature enough to spawn (c.f. Figure 3 in section 2 where the degree of maturity at age 6 is 0.4 ).

Concurrently, the parameter is adjusted with the weighted average percentage of spawners in the mature stage class.
} 
where natural growth dominates ahead of harvesting. Another set of initial conditions would yield the same steady state result, though with a different approach path.

\section{FIGURE 5 ABOUT HERE}

Detailed steady state results are shown in Table 3 . The condition $w_{3} / s_{33}>\left(w_{2}-\rho \lambda^{*} s_{22}\right) / s_{23}$ is confirmed to hold, albeit slightly, as $5.5>5.16$, and where the shadow value of the recruitment constraint is $\lambda^{*}=s_{23} w_{3} /\left(1-\rho s_{22}\right) s_{33}=2.25$. Furthermore, in line with Result 2 , the baseline optimum level of matures $\left(X_{3}^{*}\right)$ is located to the left of the recruitment function peak value $\left(X_{3}^{\max }\right)$, which is at 77 million individuals. In a more conventional unit of measurement, the optimum steady state stock levels of immatures and matures are approximately $627(284.98 * 2.2)$ and $248(56.45 * 4.4)$ thousand tonnes, respectively. As expected, a smaller discount rate (here zero) reduces the harvest rate and increases the stock of matures, and as discussed in section 5.3 this latter effect dominates with respect to optimal yield and biomass. Thus, the steady state maximum sustainable yield harvesting (MSY) and stock levels are therefore smaller and greater, respectively, than that of the steady state maximum yield (MY) (line two, Table 3). On the other hand, with a relatively high discount rate of 10 percent we see that harvest of immatures should be prioritised. This regime switch can be traced back to the above inequality condition where the discount rate both has a direct effect, as well as an indirect effect through the shadow value $\lambda^{*}$ so that the sign of this inequality changes to $w_{3} / s_{33}<\left(w_{2}-\rho \lambda^{*} s_{22}\right) / s_{23}$. Therefore, in our case with a discount rate of 10 percent it is not beneficial to wait for the fish to grow and double its weight. In accordance with Result 3, the weights do not affect harvesting or stock levels, unless the weight difference becomes too small for the baseline inequality condition to hold, at which point harvest of the immatures is preferred. For the results shown here, this happens when $w_{2}=3$ (kg/fish) (line five, Table 3$)$.

\section{TABLE 3 ABOUT HERE}

The parameters in the recruitment function have no direct influence on harvesting priority; that is, which of the stocks should be targeted. However, they influence the harvest level and the stock sizes through the slope of the recruitment function. With $R^{\prime}\left(X_{3}\right)=r \frac{1-(\eta-1)\left(X_{3} / K\right)^{\eta}}{\left[1-\left(X_{3} / K\right)^{\eta}\right]^{2}}$, and where $R^{\prime}\left(X_{3}\right)$ is determined and fixed through the optimality conditions (section 5.3), we hence find that a smaller maximum recruitment per spawning individual $r$ is consistent with a smaller mature stock size to keep $R^{\prime}\left(X_{3}\right)$ fixed. Through the recruitment function and equation (4') written as $X_{2}=$ $\left(\frac{s_{12}}{1-s_{22}}\right) R\left(X_{3}\right)$ when $h_{2}^{*}=0$ (see also section 5.2 above), a reduction in both $r$ and $X_{3}$ (given that $X_{3}$ 
initially is to the left of the peak value) spills over to a relatively large decrease in the stock of immature fish. Due to the dual effect upon $X_{2}$, the number of immature fish is reduced at a greater proportion than the number of mature fish and thus according to the spawning constraint (3') $X_{3}=$ $s_{23} X_{2}+s_{33}\left(1-h_{3}\right) X_{3}$ the harvest rate of matures is decreased (line eight, Table 3 ).

With reduced value of the compensation parameter and assuming $\eta=1.1$, we still have the domed curve of Ricker, though with weaker density effects, which may be interpreted as less cannibalism. In this case we get a somewhat higher steady state stock of both immatures and matures, correspondingly the harvesting rate $h_{3}$ is reduced. As mentioned $K$ acts as a scaling parameter and thus a greater threshold level indicates that the mature stock size must increase in the same proportion to keep $R^{\prime}\left(X_{3}\right)$ fixed. Again, from Eq. (4'), it is also then evident that $X_{2}^{*}$ must change in the same proportion as $X_{3}^{*}$ to keep $R^{\prime}\left(X_{3}\right)$ fixed. When the stock sizes change in the same proportion it is furthermore clear from Eq. (3') that the fishing mortality $h_{3}^{*}$ will stay unchanged such that we still have $h_{3}^{*}=0.76$ (line seven).

Finally, Table 3 includes results that follow from greater natural mortality, which is captured by lowering the combined survival and transition parameters, $s_{12}, s_{22}, s_{23}$ and $s_{33}$ (see Appendix). Here too, the regime switch is easily explained by the inequality $w_{3} / w_{2}>\left(s_{33}\left(1-\rho s_{22}\right)\right) / s_{23}$. When inserting for the survival and transition parameters as defined in the Appendix it is obvious that greater natural mortality requires a larger weight difference for the harvest of matures to still be optimal. In a similar manner, we find that a smaller proportion of individuals that transition from the immature to the mature stage class also require a greater weight difference for the matures to be prioritised.

\subsection{Imperfect Selectivity}

With $w_{3} / s_{33}>\left(w_{2}-\rho \lambda^{*} s_{22}\right) / s_{23}$, as predicted by Results 4 and 5 , it is always optimal to prioritise the harvest of mature fish. When the combined degree of bycatch is less than one $\left(\alpha_{2} \alpha_{3}<1\right)$ it is optimal to do so using the coastal fleet, whereas the trawler fleet is the most efficient when the combined degree of bycatch is greater than one $\left(\alpha_{2} \alpha_{3}>1\right)$. Figure 6 demonstrates the transitional dynamics in these two cases with the baseline parameter values and the same initial stock sizes as above. The harvest rates increase gradually also when there is imperfect selectivity. Figure 6 reveals that steady state harvesting rates drop compared to the baseline scenario of perfect selectivity. This was suggested in the theoretical analysis leading up to Result 6, and it follows intuitively from the fact that for each unit of harvesting effort there will be some bycatch in addition to the target stock. Thus, in order not to overexploit the resource, it is optimal to reduce the steady state harvest rate. 


\section{FIGURE 6 ABOUT HERE}

Detailed steady state results are shown in Table 4, where we see that bycatch reduce the optimal harvest rate in all considered cases. Further, bycatch decreases the stock of immatures while the stock of matures is unchanged. However, we have not been able to show this analytically ${ }^{8}$. The numerical illustrations reveal that while the introduction of bycatch increase the total number of fish caught, the distortion effect dominates and $\partial Y^{m s y} / \partial \alpha_{i}<0$ as well as $\partial Y^{*} / \partial \alpha_{i}<0(i=1,2)$ hold due to the weight difference, i.e. $w_{3}>w_{2}$. Moreover, when $\alpha_{2} \alpha_{3}<1$ there is, as expected, no effect of $\alpha_{3}$ as $h_{2}^{*}=0$, hence with a combined degree of bycatch less than one it is the bycatch of the coastal fleet $\alpha_{2}$ that dictates the outcome (lines four and five, Table 4). When $\alpha_{2}=1$, there is no real selectivity as $f_{3}=f_{2}=h_{3}$. However, when the trawler fleet still has some selectivity in favour of immatures only the coastal fleet is utilized. As indicated (section 6), when the combined degree of bycatch is one there is one degree of freedom in the system and both fleets may be utilised. In the case presented here $\alpha_{2}=$ $\alpha_{3}=1$, implying that neither fleet has any selectivity, and thus it should not matter how the harvest is distributed between the two fleets (line six). Moreover, this suggest that optimal total fishing mortality is 0.26 and the set of optimal harvesting combinations is determined by $f_{2}=f_{3}=h_{2}+h_{3}=0.26$. Similarly, for $\alpha_{2} \alpha_{3}>1$, changing $\alpha_{2}$ does not affect the outcome and the case of $\alpha_{3}=1$, is equivalent to the above combination of $\alpha_{2} \alpha_{3}<1$ and $\alpha_{2}=1$; one harvesting fleet with no real selectivity and thus $f_{3}=f_{2}=h_{2}$. When instead increasing the trawler fleet's bycatch there is quite naturally a decrease in the harvest rate as one unit of harvesting effort now yields a greater return of the byacatch stock, mature fish. These results therefore shed some light on aspects not discovered in the analytical section; it is evident that while it is the combined degree of bycatch that determines which stock should be harvested, each of the fleets' individual rates of bycatch do affect the level of harvesting.

\section{TABLE 4 ABOUT HERE}

\section{Sharing the fish stocks}

As demonstrated above, $h_{2, t}=0$ and $0<h_{3, t}<1$ represents the perfect selectivity yield maximizing, given the condition $w_{3} / s_{33}>w_{2} / s_{23}-\rho \lambda_{t+1} s_{22} / s_{23}$. Only utilizing the coastal fleet will also represent the optimal fishing policy with imperfect fishing selectivity when the bycatch is restricted as defined by $\alpha_{2} \alpha_{3}<1$. On the other hand, with $\alpha_{2} \alpha_{3}>1$ it is optimal

\footnotetext{
${ }^{8}$ The same also happens when studying the effects of changing sharing rule. Under this harvesting scheme, however, we are able to show this effect analytically. See Result 8 and Table 5 below.
} 
to only use the trawler fleet such that $h_{3, t}=0$. Thus, although the degree of selectivity affects which stage class it is optimal to target, it is generally not optimal to target both stage classes simultaneously, except when the combined degree of bycatch equals one.

The Norwegian share of the NEA cod is allocated between trawlers and the coastal fleet according to a sharing rule known as the trawl ladder. Although it varies according to the size of the TAC, the biomass share of the coastal fleet is always greater than that of the trawlers. According to our findings, a sharing rule imposes a non-optimal harvesting regime, and in order to study the implications of this we introduce a sharing rule in the form of a constraint on our problem. Assume the sharing rule allocates a certain fraction $0<\gamma \leq 1$ of the coastal fleet's yearly harvested biomass to the trawlers, i.e. the fleet harvesting the immature stock. While only the perfect selectivity case is analysed analytically, both perfect and imperfect selectivity are examined in the numerical illustrations. Hence, with perfect fishing selectivity, the distributional constraint imposed by the trawl share is stated as:

$$
w_{2} X_{2, t} h_{2, t} \geq \gamma w_{3} X_{3, t} h_{3, t} .
$$

With $\varphi_{t}>0$ as the shadow price reflecting this distributional constraint, the Lagrangian of this new yield maximizing problem is written as

$$
\begin{aligned}
& L=\sum_{t=0}^{\infty} \rho^{t}\left\{\left(w_{2} h_{2, t} X_{2, t}+w_{3} h_{3, t} X_{3, t}\right)-\rho \lambda_{t+1}\left[X_{2, t+1}-s_{12} R\left(X_{3, t}\right)-s_{22}\left(1-h_{2, t}\right) X_{2, t}\right]-\right. \\
& \left.\rho \mu_{t+1}\left[X_{3, t+1}-s_{23}\left(1-h_{2, t}\right) X_{2, t}-s_{33}\left(1-h_{3, t}\right) X_{3, t}\right]-\varphi_{t}\left[\gamma w_{3} X_{3, t} h_{3, t}-w_{2} X_{2, t} h_{2, t}\right]\right\} .
\end{aligned}
$$

The optimal first order conditions are now:

$$
\left(\partial L / \partial h_{2, t}\right) / \rho^{t}=X_{2, t}\left(w_{2}-\rho \lambda_{t+1} s_{22}-\rho \mu_{t+1} s_{23}+\varphi_{t} w_{2}\right)=0 ; 0<h_{2, t}<1, t=
$$

$0,1,2 \ldots$,

$$
\left(\partial L / \partial X_{2, t}\right) / \rho^{t}=w_{2} h_{2, t}-\lambda_{t}+\rho \lambda_{t+1} s_{22}\left(1-h_{2}\right)+\rho \mu_{t+1} s_{23}\left(1-h_{2}\right)+\varphi w_{2} h_{2, t}=
$$
$0 ; t=1,2,3 \ldots$

and 


$$
\left(\partial L / \partial X_{3, t}\right) / \rho^{t}=w_{3} h_{3, t}+\rho \lambda_{t+1} s_{12} R^{\prime}\left(X_{3, t}\right)-\mu_{t}+\rho \mu_{t+1} s_{33}\left(1-h_{3}\right)-
$$

$\varphi \gamma w_{3} h_{3, t}=0 ; t=1,2,3 \ldots$.

Combined, the two control conditions (20) and (21) may be written as $\left(\frac{w_{3}}{s_{33}}-\frac{\rho \varphi_{t} \gamma w_{3}}{s_{33}}\right)=$ $\left(\frac{w_{2}}{s_{23}}-\frac{\rho \lambda_{t+1} s_{22}}{s_{23}}+\frac{\rho \varphi_{t} w_{2}}{s_{23}}\right)=\rho \mu_{t+1}$. The distributional constraint operates as a cost factor imposing a positive unit cost on the coastal fleet and a negative unit cost, or a subsidy, on the trawler fleet. Concurrently, although we study the maximum yield problem and not that of MEY, costs in terms of biomass will be higher with the existence of a sharing rule, indicating inefficiency. This is stated as:

Result 7: The distributional constraint inherent in the sharing rule has a two-fold effect. For the costal fleet it operates as a negative unit cost, whereas it for the trawlerfleet acts as a unit subsidy.

In steady state condition (21) may be written as $\mu=\frac{w_{3}(1-\varphi \gamma)}{\rho s_{33}}$, indicating that the shadow value ( $\mathrm{kg} / \mathrm{fish})$ of the mature stock is lower when there is a distributional constraint. Additionally, condition (20) can be used to show that immatures are more valuable compared to the situation without a distributional constraint; that is, $\lambda=\frac{1}{\rho s_{22}}\left(w_{2}(1+\varphi)-\right.$ $\left.\frac{w_{3}(1-\varphi \gamma) s_{23}}{s_{33}}\right)$. By using Eq. (22), the shadow price of the distribution constraint can be written as $\varphi=\left(w_{2}\left(1-\rho s_{22}\right)-\frac{s_{23}}{s_{33}} w_{3}\right) /\left(w_{2}\left(\rho s_{22}-1\right)-\frac{s_{23}}{s_{33}} w_{3} \gamma\right)$. Next, the shadow values may be inserted into Eq. (23) where after some rearrangements the harvest rate cancels out, and we find that the slope of the recruitment function can be written as $R^{\prime}\left(X_{3}\right)=\frac{\left(1-\rho s_{22}\right)\left(1-\rho s_{33}\right)}{\rho^{2} s_{23} s_{12}}$. That is, the identical outcome as when no distributional constraint was included (section 5.3 above). Therefore, the size of the optimized mature stock $X_{3}$ is independent of the distributional constraint. This is stated as:

Result 8: The optimal steady state stock of matures is independent of the harvesting share allocated to the fleet targeting immatures.

This is indeed a surprising result, but while $X_{3}$ is unaffected by the trawler harvesting share, it is evident from Eq. (3') that $X_{2}$ as well as the harvest rate of the immatures will be 
influenced. More precisely, there must exist an exact trade-off between the harvest induced reduction in the stock of immatures and thus the number of individuals that transfer to the mature stage class, and the reduction in the harvest rate of matures, hence leaving the stock of matures unchanged.

How the trawler's share influence yield is again analysed in steady state with zero discount rent, i.e. in the maximum sustainable yield (MSY) scenario. Based on the direct approach and omitting the shadow prices (see section 6 above), MSY may now be expressed as $Y^{m s y}=w_{2} X_{2}^{m s y}\left(h_{2}(\gamma), h_{3}(\gamma), \gamma\right) h_{2}(\gamma)+w_{3} X_{3}^{m s y}\left(h_{2}(\gamma), h_{3}(\gamma)\right) h_{3}(\gamma)$ when Result 8 is taken into account such that the distributional constraint has no direct effect on the mature stock size. Differentiating with respect to $\gamma$ and using the envelope theorem, we have $\partial Y^{m s y} / \partial \gamma=w_{2}\left(\partial X_{2}^{m s y} / \partial \gamma\right) h_{2}^{m s y}$. With $\partial X_{2}^{m s y} / \partial \gamma<0$ we find $\partial Y^{m s y} / \partial \gamma<0$, which is expected as any $\gamma>0$ is assumed to be non-optimal. Figure 7 illustrates for the original maximum yield (MY) problem where the total steady state yield declines quite modestly as a higher harvesting share is allocated to the trawler fleet. When half of the fished biomass is allocated to the trawler fleet, $\gamma=0.50$, the maximum biomass yield is about $94 \%$ of the yield without any sharing constraint. Again, the decline in biomass is driven by the weight difference between immatures and matures, as the total number of fish caught increase. However, the modest effect can also be traced back to the stage based formulation of our model and the large differences between the pure survival rate $s_{33}$ and the survival rates also reflecting transition between the immature and mature stages (section 5.2 and Appendix).

\section{FIGURE 7 ABOUT HERE}

Table 5 gives more detailed numerical results, and where Result 7 is mirrored through the cost effect of the sharing rule that reduces the optimal harvest rate of matures, while the subsidy effect increases the harvest rate of immatures. Additionally, the stock of matures remain unaffected, as predicted by Result 8 .

\section{TABLE 5 ABOUT HERE}

In Table 6 the numerical illustrations including imperfect perfect selectivity are presented with the sharing fraction $\gamma=0.5$. When the combined degree of bycatch is less than one, harvesting rates are less than without bycatch, yet the same pattern may be identified. These numerical results reveal that the distributional constraint does not bind when the combined 
degree of bycatch is above one. This follows from the fact that the distributional constraint does not secure a minimum fraction of harvest for the coastal fleet, and when combined bycatch is above one it is as demonstrated optimal to only utilize the trawler fleet.

\section{TABLE 6 ABOUT HERE}

\section{Concluding remarks}

Using a stage structured model with a domed Shepherd recruitment function we have studied maximum sustainable yield (MSY) and maximum yield (MY), as well as optimal harvest composition in a fishery with two heterogeneous fleets. The stage model developed here bundles the age classes into stage classes based on their level of maturity, but also the pattern according to which they are harvested. There are two stages included in the harvestable stock; immatures and matures. In many fisheries, as in the Northeast Arctic (NEA) cod fishery, it is a clear distinction between coastal and high-sea fishing. In the NEA fishery, the coastal fleet mainly targets mature cod while the high-sea trawler fleet targets immature cod. This study considers both perfect selectivity (pure mature and immature catches) and mixed catches in the two fleets. In the case of perfect selectivity, it is optimal only to harvest mature cod and invest the immature cod in the coastal fishery. The simple rational behind is that the surviving cod reaches a higher total biomass after maturation. It also demands a certain restriction in the variation of survival and transition rates among the different stages. This is in contrast to age structured models where these rates are pure survival rates. Moreover, we find that it optimal to harvest to such an extent that cannibalism is curbed. This result remains after introducing imperfect fishing selectivity and mixed catches. In this case it may however be optimal to utilise both fleets depending on the selective properties of the fishing gear. At moderate levels of bycatch it is still optimal to utilize the coastal fleet while the trawler fleet is more efficient at higher bycatch levels. In all fishing schemes with the baseline parameter values the optimal solution is to prioritise harvest of the mature fraction of the stock. This study also shows that sharing rules that implicitly or explicitly entail the harvest of both immature and mature cod generate efficiency losses. However, following our numerical illustrations the losses is quite small which basically hinges on the stage based model formulation with large differences between pure survival rates and survival rates also reflecting transition between the immature and mature stages. We also find that while the size 
of the sharing rule influences the optimal harvest of the immature stock as well as the harvest rates while the size of the mature stock is unaffected.

Fishing costs and the concept of maximum economic yield (MEY) have not been analysed in this study. If costs should be introduced our results would tend to be more ambiguous. With a higher unit cost of harvest in the costal fleet than in the trawler fleet our main findings may be reversed from prioritising catch of mature cod to giving priority of targeting immature cod. However, in the NEA cod fishery the cost structure seems to be in line with our results; that is, the unit cost of harvesting is less for the coastal fleet than for the trawler fleet (Inarra and Skonhoft 2008; Sumaila 1997). There seems also to be a price premium for mature fish as the market price per $\mathrm{kg}$ typically is higher for larger fish than smaller fish (Armstrong and Sumaila 2000; Zimmermann et al. 2011). Additionally, there are relevant external costs not taken into account in the present analysis, including the potential evolutionary consequences of selective harvesting (e.g., Olsen et al. 2004), and certain costs that most likely is higher for the trawlers than for the coastal fleet. Such costs include the carbon footprint of the vessel groups, where the coastal fleets are more fuel-efficient than trawlers. While Norwegian handline and gillnet boats on average use 0.15 litre diesel per kilo fish harvested, the Norwegian bottom trawlers use 0.43 (Winther et al. 2009). Another externality that may be of importance is the well-known potential habitat damage from bottom trawling.

\section{Appendix}

\section{Survival and transition parameters}

The so-called survival and transition parameters exhibit the individual's movement through the different stage classes. Let $m_{i}$ denote natural mortality of stage $i$, such that the probability of surviving one year in stage $i$ is $\left(1-m_{i}\right)$. Furthermore, we follow the example of Getz and Haight (1989) and let $0<p_{i} \leq 1$ denote the proportion of individuals in stage class $i$ that move into stage class $i+1$ in the time interval $(t, t+1)$. Accordingly, $\left(1-p_{i}\right)$ is the proportion that remain in stage class $i$ an additional year. This information enables the construction of the composite survival and transformation parameters.

The pure survival rates; the proportion of individuals that survive the time interval $(t, t+1)$ and remain within their stage class $i$, is defined as: 
(A1) $s_{i i}=\left(1-p_{i}\right)\left(1-m_{i}\right)$.

The survival and transition parameters; the proportion of individuals that survive the time interval $(t, t+1)$ and move on to the next stage class $i+1$, is accordingly defined as:

(A2) $s_{i, i+1}=p_{i}\left(1-m_{i}\right)$.

The stage class of immature fish consist of five age classes; that is. fish of age 1, 2,3,4 and 5 years. Thus, one might assume that approximately one fifth (1/5) of the immatures move into the mature stage class each year such that $p_{2}=0.2$. As an example, consider $s_{33}$ and $s_{23}$ as these prove to be crucial to the above discussion (section 5.1). First, $s_{23}$ is the proportion of immatures that survive the one year period $(t, t+1)$ and move on to the mature stage class. Thus, the parameter is determined by $p_{2}$ and $m_{2}$, the natural mortality of immatures. In line with Anon (2016) natural mortality for all stage classes is 0.2 and hence we have $s_{23}=0.2 *$ $(1-0.2)=0.16$. Secondly, as the mature class is the final stage class there is no more transition $\left(p_{3}=0\right)$ and $s_{33}$ is a pure survival rate, i.e. it is the proportion of matures that survive the one year period $(t, t+1)$. Correspondingly $s_{33}=(1-0) *(1-0.2)=0.8$, and thus it is shown that the difference between $s_{33}$ and $s_{23}$ is quite substantial.

\section{References}

Anon. (2013). Report of the Arctic Fisheries Working Group (AFWG). ICES CM 2013/ACOM:05.

Anon. (2016). Report of the Arctic Fisheries Working Group (AFWG). ICES CM 2016/ACOM:06.

Armstrong, C. W. (1999), 'Sharing a fish resource - bioeconomic analysis of an applied allocation rule', Environmental and Resource Economics 13, 75-94.

Armstrong, C. W. and Sumaila, U. R. (2000), 'Cannibalism and the optimal sharing of the north-east atlantic cod stock: a bioeconomic model', Journal of Bioeconomics 2(2), 99115 . 
Armstrong, C. W., Eide, A., Flaaten, O., Heen, K. and Kaspersen, I. W. (2014), 'Rebuilding the northeast arctic cod fisheries - economic and social issues', Arctic Review on Law and Politics 5(1), 11-37.

Arnason, R., Sandal, L. K., Steinshamn, S. I., Vestergaard, N., (2004) 'Optimal feedback controls: comparative evaluation of the cod fisheries in Denmark, Iceland and Norway’ American Journal of Agricultural Economics 86 (2), 531-542.

Beverton, R. J. H. and Holt, S. J. (1957), On the dynamics of exploited fish populations, Vol. XIX of Fishery Investigations Series, Her Majesty's Stationary Office.

Bogstad, B., Lilly, G. R., Mehl, S., Palsson, O. K. and Stefansson, G. (1994), 'Cannibalism and year-class strength in atlantic cod (gadus morhua 1.) in arcto-boreal ecosystems (barents sea, iceland and eastern newfoundland)', ICES Marine Science Symposia (198), 576-599.

Caswell, H. (2001), Matrix population models: construction, analysis and interpretation, Sinauer Associates.

Clark, C. W. (1990), Mathematical Bioeconomics Optimal Management of Renewable Resources, 2ed., Wiley.

Clucas, I. (1997) A study of the options for utilization of bycatch and discards from marine capture fisheries. FAO Fisheries Circular C928, Rome.

Diekert, F. K. (2013), 'The growin value of age: exploring economic gains from age-specific harvesting in the northeast arctic cod fishery', Canadian Journal of Fisheries and Aquatic Sciences 70, 1346-1358.

Diekert, F. K., Hjermann, D. Ø., Nævdal, E. and Stenseth, N. C. (2010a), 'Non-cooperative exploitation of multi-cohort fisheries - the role of gear selectivity in the north-east arctic cod fishery', Resource and Energy Economics 32, 78-92.

Diekert, F. K., Hjermann, D. Ø., Nævdal, E. and Stenseth, N. C. (2010b), 'Spare the young fish: Optimal harvesting policies for north-east arctic cod', Environmental Resource Economics 47, 455-475.

Directorate of Fisheries (2016), Profitability survey on the Norwegian fishing fleet 2014. Online. 
Eide, A. and Wikan, A. (2010), Optimal selection and effort in a fishery on a stock with cannibalistic behaviour the case of the northeast arctic cod fisheries', Journal of Fisheries and Aquatic Sciences 5, 454-468.

Eide, A., Heen, K., Armstrong, C. W., Flaaten, O. and Vasiliev, A. (2013), 'Challenges and successes in the management of a shared fish stock the case of the Russian-Norwegian Barents sea cod fishery', Acta Borealia 30, 1-20.

Getz, W. M. and Haight, R. G. (1989), Population Harvesting - Demographic models of fish, forest and animal resources, Princeton University Press.

Gullestad, P., Bloom, G., Bakke, G. and Bogstad, B. (2015). 'The «Discard Ban Package»: Experiences in efforts to improve the exploitation patterns in Norwegian fisheries' Marine Policy, 54, 1-9.

Hannesson, R. (1975), 'Fishery dynamics: A North Atlantic cod fishery', The Canadian Journal of Economics 8, 151-173.

Inarra, E. and Skonhoft, A. (2008), 'Restoring a fish stock: A dynamic bankruptcy problem', Land Economics 84, 327-339.

King, M. (1995), Fisheries Biology, Assessment and Management, Fishing News Books.

Myers, R. A., Mertz, G. and Fowlow, P. S. (1997), Maximum population growth rates and recovery times for Atlantic cod gadus morhua, Fishery Bulletin 95, 762-772.

Olsen, E. M., Heino, M., Lilly, G. R., Morgan, M. J., Brattey, J., Ernande, B. and Dieckmann, U., (2004) 'Maturation trends indicative of rapid evolution preceded the collapse of Northern Cod' Nature, 428 (6986) 932-935.

Ottersen, G., (2008) 'Pronounced long-term juvenation in the spawning stock of arctonorwegian cod (Gadus morhua) and possible consequences for recrtuitment', Canadian Journal of Fisheries and Aquatic Sciences, 65 (3), 523-534.

Quaas, M. F., Requate, T., Ruckes, K., Skonhoft, A., Vestergaard, N. and Voss, R. (2013), 'Incentives for optimal management of age-structured fish populations', Resource and Energy Economics 35, 113-134. 
Quinn, T. (2003), 'Ruminations on the development and future of population dynamic models in fisheries', Natural Resource Modeling 16, 341 - 392

Reed, W. J. (1980), 'Optimum age-specific harvesting in a nonlinear population model', Biometrics 36, 579-593.

Shepherd, J. G. (1982) A versatile new stock-recruitment relationship for fisheries, and the construction of sustainable yield curves. ICES Journal of Marine Science 40 (1), 67 75.

Singh, R. and Weninger, Q. (2009), Bioeconomies of scope and the discard problem in multispecies fisheries, Journal of Environmental Economics and Management 58, 7292.

Skonhoft, A. and Gong, P. (2014), 'Wild salmon fishing: Harvesting the old or young?', Resource and Energy Economics 36, 417-435.

Skonhoft, A., Vestergaard, N. and Quaas, M. (2012), 'Optimal harvest in an age structured model with different fishing selectivity', Environmental Resource Economics 51, 525544.

Sumaila, U. R. (1997), 'Cooperative and non-cooperative exploitation of the arcto-norwegian cod stock', Environmental and Resource Economics 10, 147-165.

Steinshamn, S. I. (2005) Ressursrenten i norske fiskerier. SNF rapport nr. 06/05

Tahvonen, O. (2008), 'Harvesting an age-structured population as biomass: does it work?', Natural Resource Modeling 21

Tahvonen, O. (2009), 'Economics of harvesting age-structured fish populations', Journal of Environmental Economics and Management 58, 281-299.

Wikan, A. and Eide, A. (2004), 'An analysis of a nonlinear stage-structured cannibalism model with application to the northeast arctic cod stock', Bulletin of Mathematical Biology 66, 1685-1704.

Wilen, J. (2000),'Renewable resource economists and policy: What differences have we made', Journal of Environment Economics and Management 39, 306-327. 
Winther, U. (2011), Carbon footprint and energy use of Norwegian seafood products, SINTEF report, Fisheries and Aquaculture.

Yaragina, N. A., Bogstad, B. and Kovalev, Y. A. (2009), 'Variability in cannibalism in northeast arctic cod (gadus morhua) during the period 1974-2006', Marine Biology Research 5, 75-85.

Zimmermann, F., Heino, M. and Steinshamn, S. I. (2011), 'Does size matter? a bioeconomic perspective on optimal harvesting when price is size-dependent', Canadian Journal of Fisheries and Aquatic Sciences 68, 1651-1659.

\section{Figures and Tables}




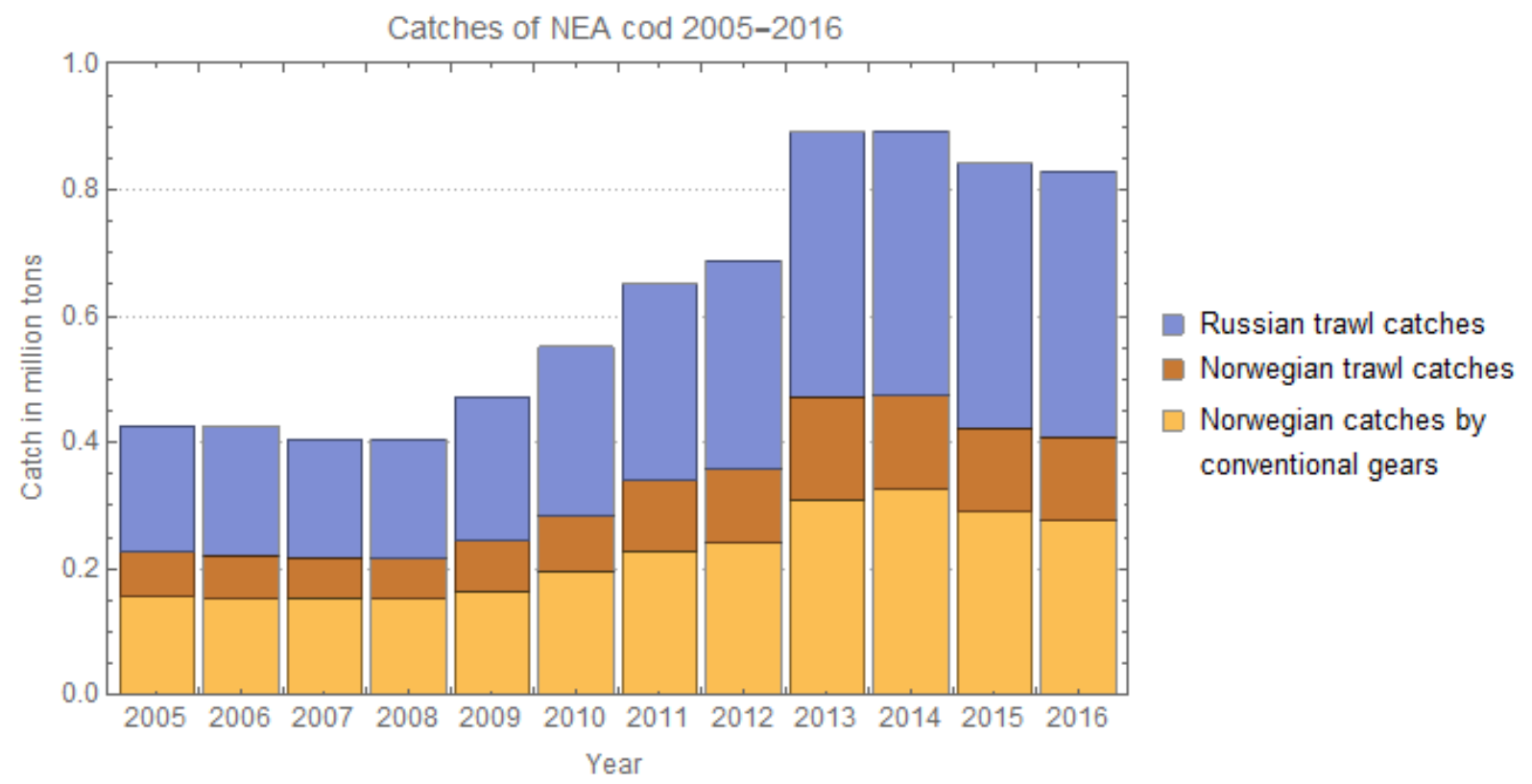

Figure 1. Russian and Norwegian catches of NEA cod 2005-2013 (Source: Norwegian fisheries directorate and Anon., 2017).

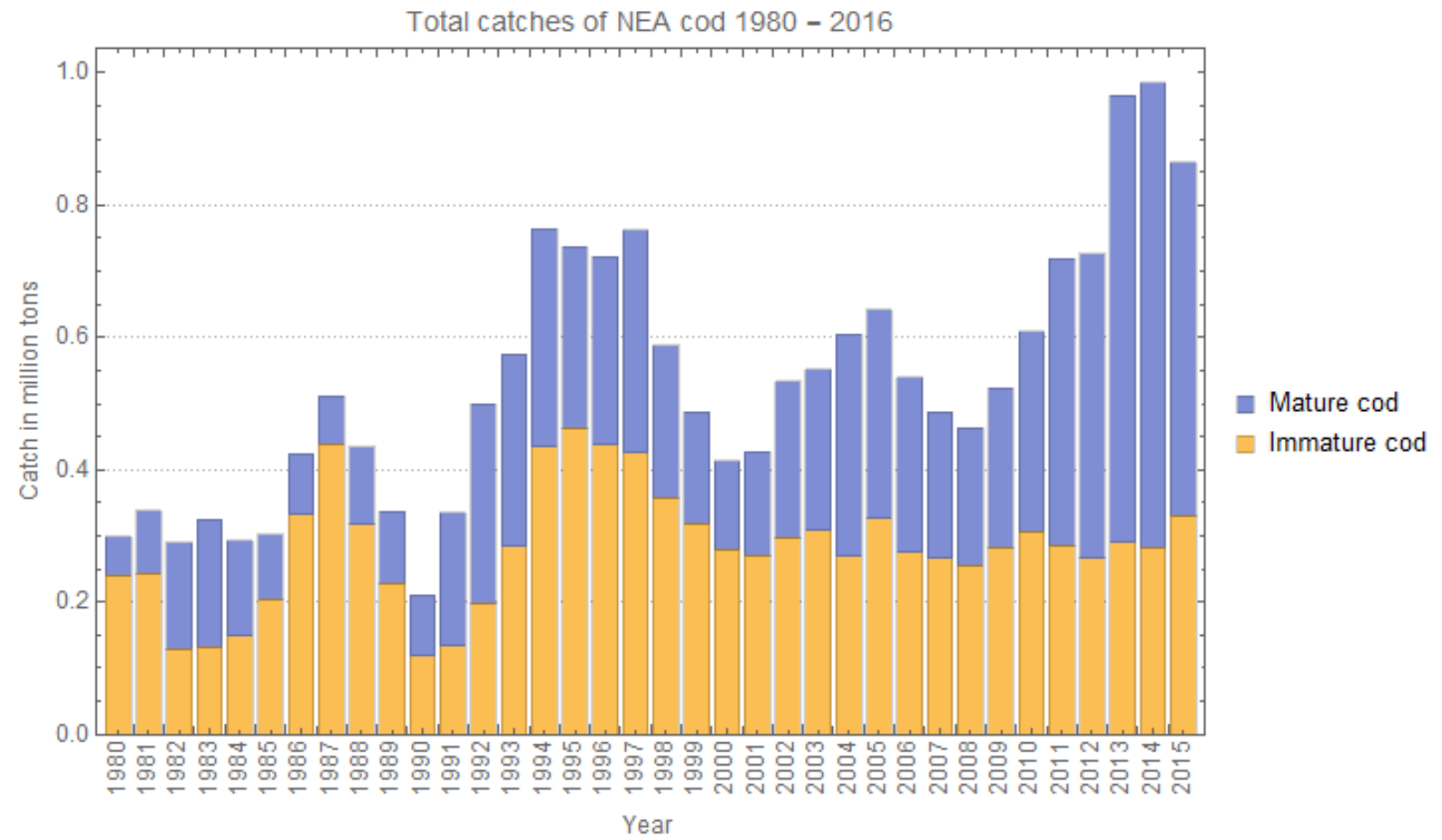

Figure 2. Total catch of NEA cod 1980-2015. Mature and immature fish (Anon., 2016). 

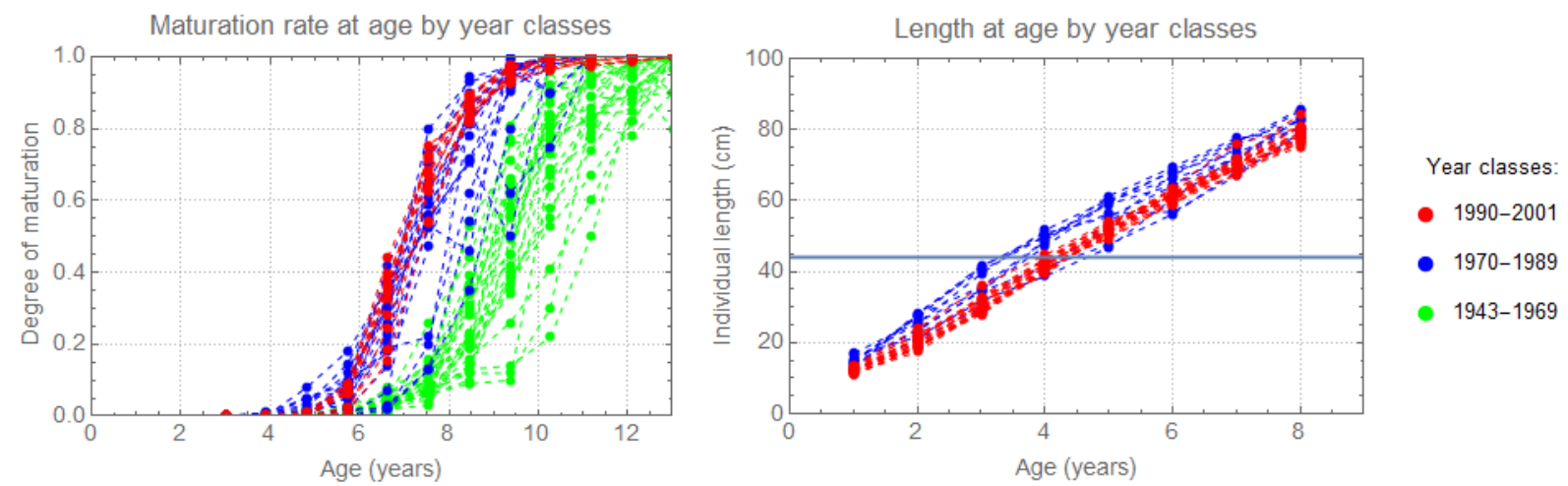

Figure 3. Maturation level at age in different year classes of NEA cod (left panel) and individual length at age by year classes (right panel). Length data for year classes before 1980 was not available. The thick horizontal line in the right panel indicates the current minimum size (44 cm fish length) in the cod fishery regulation (Data source: Anon., 2016).

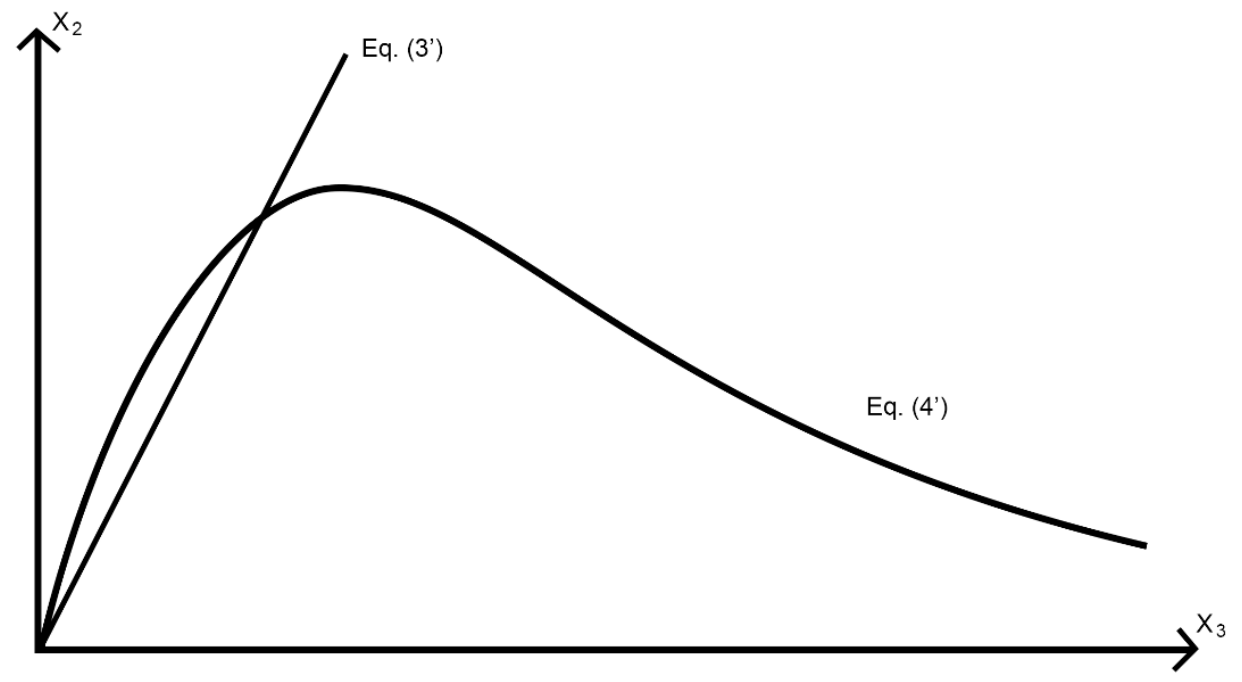

Figure 4. Biological equilibrium with fixed fishing mortalities. The spawning constraint Eq. (3') and recruitment constraint (Shepherd type recruitment function) Eq. (4'). 

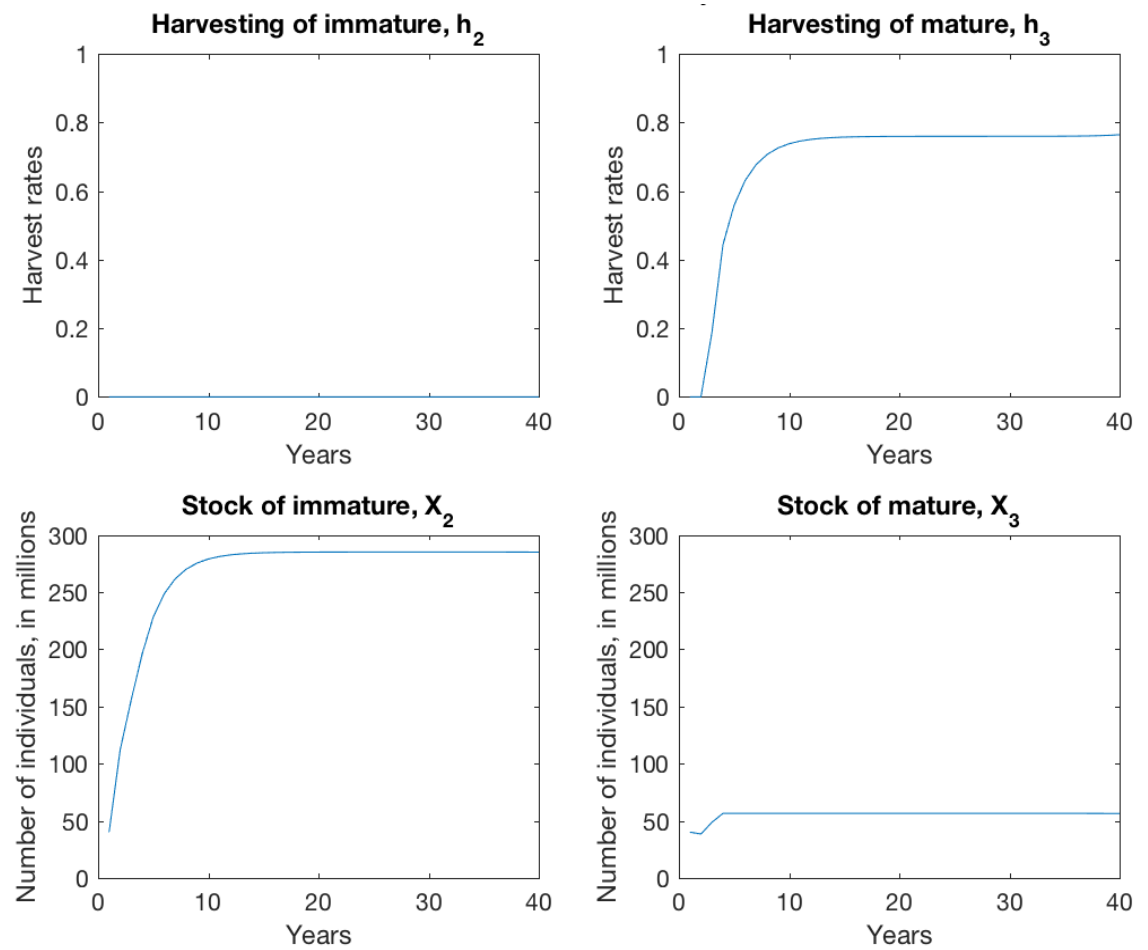

Figure 5. Transitional dynamics perfect selectivity. Baseline parameter values.
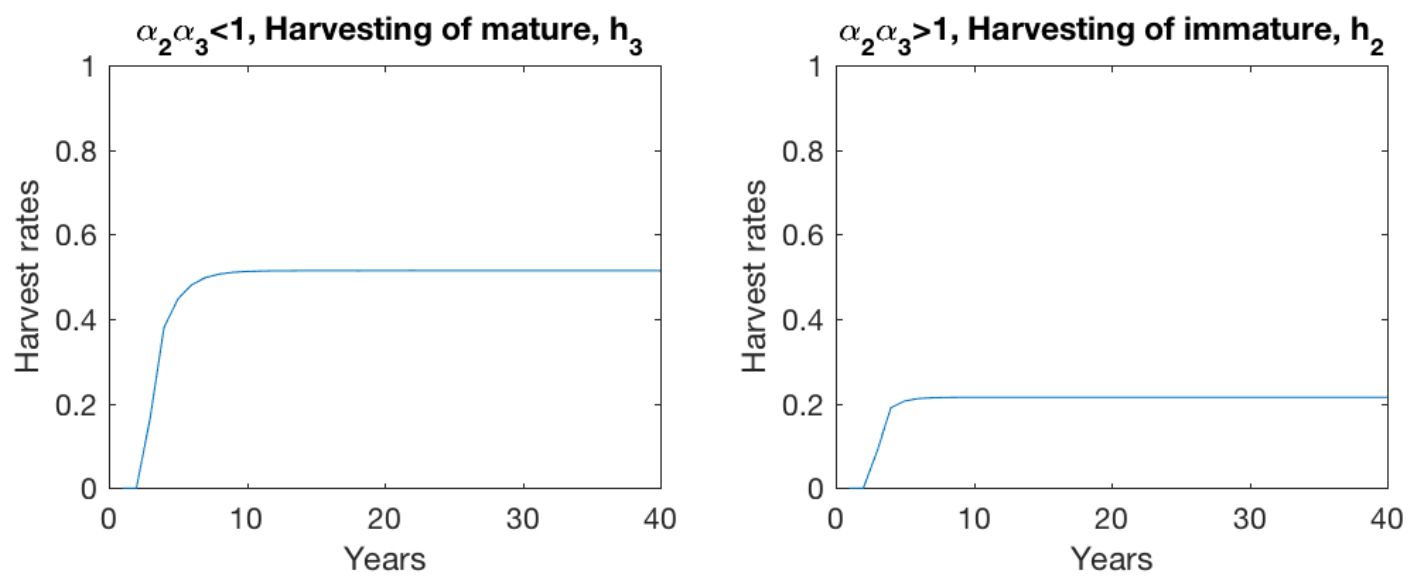

Figure 6. Transitional dynamics imperfect selectivity. Baseline parameter values. $\alpha_{2} \alpha_{3}<1$ with $\alpha_{2}=0.2$ and $\alpha_{3}=0.5 . \alpha_{2} \alpha_{3}>1$ with $\alpha_{2}=0.8$ and $\alpha_{3}=1.5$. 


$$
\begin{aligned}
& \text { Total yield (in } \\
& \text { thousand tonnes) }
\end{aligned}
$$

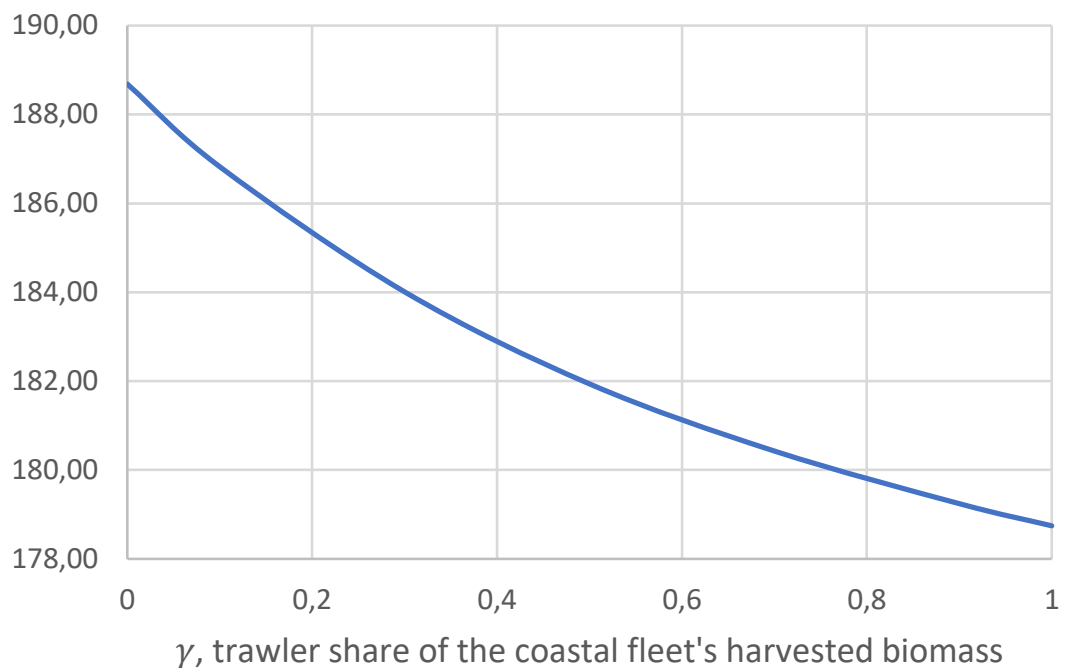

Figure 7. Steady state maximum yield (MY) and the trawler share. Baseline parameter values.

\begin{tabular}{|c|c|c|c|c|}
\hline & $w_{2}$ & $w_{3}$ & $\delta$ & $S$ \\
\hline$h_{3}^{*}$ & 0 & 0 & + & - \\
\hline$X_{2}^{*}$ & 0 & 0 & - & + \\
\hline$X_{3}^{*}$ & 0 & 0 & - & + \\
\hline$Y^{*}$ & 0 & + & ? & + \\
\hline$B^{*}$ & + & + & - & + \\
\hline
\end{tabular}

Table 1. Steady state comparative statics. Perfect selectivity.

Table note: All survival rates are working in the same direction and is abbreviated by using the notation $S$. 
Table 2. Biological and economic baseline parameter values.

\begin{tabular}{|c|c|c|c|}
\hline Parameter & Description & Value & Source \\
\hline$s_{12}$ & Natural survival rate recruits. & 0.80 & Anon. (2016) \\
\hline$s_{22}$ & $\begin{array}{l}\text { Proportion that survives and } \\
\text { remain in the immature stage class }\end{array}$ & 0.64 & $\begin{array}{l}\text { Based on Anon. } \\
\text { (2016) }\end{array}$ \\
\hline$s_{23}$ & $\begin{array}{l}\text { Proportion that survives and } \\
\text { transition from immatures to } \\
\text { matures }\end{array}$ & 0.16 & $\begin{array}{l}\text { Based on Anon. } \\
\text { (2016) }\end{array}$ \\
\hline$s_{33}$ & Natural survival rate matures. & 0.80 & Anon. (2016) \\
\hline$\eta$ & Compensation parameter & 2.2 & $\begin{array}{c}\text { Based on Shepherd } \\
(1982)\end{array}$ \\
\hline$r$ & $\begin{array}{c}\text { Number of recruits per mature } \\
\text { individual }\end{array}$ & 3.2 & $\begin{array}{l}\text { Myers et al. (1997) } \\
\text { and Anon. (2016) }\end{array}$ \\
\hline$K$ & $\begin{array}{l}\text { Recruitment function threshold } \\
\text { level }\end{array}$ & $\begin{array}{l}84 \text { (\# million } \\
\text { individuals) }\end{array}$ & Diekert (2013) \\
\hline$w_{2}$ & Weight (average) immature fish & $2.2^{1}(\mathrm{~kg} / \mathrm{fish})$ & Anon. (2016) \\
\hline$w_{3}$ & Weight (average) mature fish & $4.4^{1}$ (kg/fish) & Anon. (2016) \\
\hline$\delta$ & Discount rate & 0.05 & Assumed \\
\hline
\end{tabular}

${ }^{1}$ Average weight of catches over ten years (2006-2015)

Table 3. Steady state and sensitivity analysis. Perfect selectivity.

\begin{tabular}{|r|cccccc|}
\hline & & & $\begin{array}{c}X_{2}^{*} \\
\text { individuals, } \\
\text { in millions) }\end{array}$ & $\begin{array}{c}X_{3}^{*} \\
\text { (individuals, } \\
\text { in millions) }\end{array}$ & $\begin{array}{c}Y^{*} \\
\text { (in } \\
\text { thousand } \\
\text { tonnes) }\end{array}$ & $\begin{array}{c}B^{*} \\
\text { (in } \\
\text { thousand } \\
\text { tonnes) }\end{array}$ \\
\cline { 2 - 7 } $\boldsymbol{M S Y}(\boldsymbol{\delta}=\mathbf{0})$ & 0.00 & 0.76 & 284.98 & 56.45 & 188.69 & 875.32 \\
$\delta=0.1$ & 0.00 & 0.70 & 292.63 & 61.52 & 189.84 & 914.47 \\
$w_{3}=5 \mathrm{~kg}$ & 0.00 & 0.76 & 284.97 & 56.45 & 300.17 & 1022.08 \\
$w_{2}=3 \mathrm{~kg}$ & 0.52 & 0.00 & 147.74 & 56.45 & 385.89 & 987.08 \\
$\eta=1.1$ & 0.00 & 0.50 & 288.97 & 77.22 & 169.36 & 975.49 \\
$K=150$ & 0.00 & 0.76 & 508.88 & 100.80 & 336.92 & 1563.04 \\
$r=1.5$ & 0.00 & 0.31 & 111.70 & 40.09 & 54.20 & 422.12 \\
$s_{12}=s_{33}=0.7 ; s_{22}$ & & & & & & \\
$=0.57 ; s_{23}=0.14{ }^{a}$ & 0.31 & 0.00 & 122.37 & 39.57 & 82.65 & 443.33 \\
$s_{12}=s_{33}=0.8 ; s_{22}$ & & & & & & \\
$=0.72 ; s_{23}=0.08^{b}$ & 0.34 & 0.00 & 180.32 & 47.34 & 135.66 & 605.01 \\
\hline
\end{tabular}

Table notes; $a$ : Survival and transition parameters when natural mortality is increased.

$b$ : Survival and transition parameters when the yearly proportion of individuals that transition from the immature to the mature stage class is reduced. 
Table 4. Steady state imperfect selectivity. Baseline parameter values.

\begin{tabular}{|c|c|c|c|c|c|c|c|c|}
\hline $\begin{array}{c}\text { Combined } \\
\text { degree of } \\
\text { bycatch, } \\
\alpha_{2} \alpha_{3}\end{array}$ & $\alpha_{2}$ & $\alpha_{3}$ & $h_{2}^{*}$ & $h_{3}^{*}$ & $\begin{array}{c}X_{2}^{*} \\
\text { (individuals, } \\
\text { in millions) }\end{array}$ & $\begin{array}{c}X_{3}^{*} \\
\text { (individuals, in } \\
\text { millions) }\end{array}$ & $\begin{array}{l}Y^{*} \\
\text { (in } \\
\text { thousand } \\
\text { tonnes) }\end{array}$ & $\begin{array}{c}B^{*} \\
\text { (in } \\
\text { thousand } \\
\text { tonnes) }\end{array}$ \\
\hline Baseline & 0 & 0 & 0.00 & 0.76 & 284.98 & 56.45 & 188.69 & 875.32 \\
\hline 0.2 & 0.2 & 1 & 0.00 & 0.51 & 241.07 & 56.45 & 182.47 & 778.73 \\
\hline 0.5 & 0.5 & 1 & 0.00 & 0.37 & 214.73 & 56.45 & 178.78 & 720.79 \\
\hline 0.2 & 1 & 0.2 & 0.00 & 0.26 & 194.95 & 56.45 & 176.23 & 677.26 \\
\hline 0.5 & 1 & 0.5 & 0.00 & 0.26 & 194.96 & 56.45 & 176.19 & 677.29 \\
\hline 1 & 1 & 1 & 0.13 & 0.13 & 195.00 & 56.45 & 176.14 & 677.37 \\
\hline 1.5 & 1.5 & 1 & 0.26 & 0.00 & 194.95 & 56.45 & 176.21 & 677.28 \\
\hline 2 & 2 & 1 & 0.26 & 0.00 & 194.97 & 56.45 & 176.24 & 677.32 \\
\hline 1.5 & 1 & 1.5 & 0.22 & 0.00 & 206.29 & 56.45 & 177.74 & 702.21 \\
\hline 2 & 1 & 2 & 0.18 & 0.00 & 214.73 & 56.45 & 178.86 & 721.78 \\
\hline
\end{tabular}

Table 5. Steady state perfect selectivity with various sharing rules. Baseline parameter values.

\begin{tabular}{|r|ccccccc|}
\hline \multicolumn{1}{r|}{} & \multicolumn{1}{|c}{$\begin{array}{c}X_{2}^{*} \\
\text { (individuals } \\
\text { in } \\
\text { millions) }\end{array}$} & $\begin{array}{c}X_{3}^{*} \\
\text { (individuals } \\
\text { in } \\
\text { millions) }\end{array}$ & $\begin{array}{c}Y^{*} \\
\text { (in thousand } \\
\text { tonnes) }\end{array}$ & $\begin{array}{c}w_{2} h_{2}^{*} X_{2}^{*} \\
\text { (in thousand } \\
\text { tonnes, fraction of } \\
\text { total in brackets) }\end{array}$ & $\begin{array}{c}w_{3} h_{3}^{*} X_{3}^{*} \\
\text { (in thousand } \\
\text { tonnes, fraction of } \\
\text { total in brackets) }\end{array}$ \\
\hline $\mathbf{0}$ & 0.00 & 0.76 & 284.97 & 56.45 & 188.68 & $0.00(0.00)$ & $188.68(1)$ \\
$\mathbf{0 . 1 0}$ & 0.03 & 0.68 & 271.26 & 56.45 & 186.82 & $16.98(0.09)$ & $169.84(0.91)$ \\
$\mathbf{0 . 3 0}$ & 0.08 & 0.57 & 250.67 & 56.45 & 184.01 & $42.46(0.23)$ & $141.54(0.77)$ \\
$\mathbf{0 . 5 0}$ & 0.12 & 0.49 & 235.97 & 56.45 & 181.94 & $60.65(0.33)$ & $121.29(0.67)$ \\
$\mathbf{0 . 7 0}$ & 0.15 & 0.43 & 224.94 & 56.45 & 180.43 & $74.29(0.41)$ & $106.13(0.59)$ \\
$\mathbf{0 . 9 0}$ & 0.18 & 0.38 & 216.36 & 56.45 & 179.24 & $84.90(0.47)$ & $94.34(0.53)$ \\
$\mathbf{1 . 0 0}$ & 0.19 & 0.36 & 212.75 & 56.45 & 178.75 & $89.37(0.5)$ & $89.37(0.50)$ \\
\hline
\end{tabular}


Table 6. Steady state with distribution constraint and bycatch. Baseline parameter values.

\begin{tabular}{|l|cccccc|}
\hline $\begin{array}{l}\text { Combined } \\
\text { degree of } \\
\text { bycatch, } \\
\alpha_{2} \alpha_{3}\end{array}$ & $h_{2}^{*}$ & $h_{3}^{*}$ & $\begin{array}{c}X_{2}^{*} \\
\text { (individuals, } \\
\text { in millions) }\end{array}$ & $\begin{array}{c}X_{3}^{*} \\
\text { (individuals, in } \\
\text { millions) }\end{array}$ & $\begin{array}{c}Y^{*} \\
\text { (in } \\
\text { thousand } \\
\text { tonnes) }\end{array}$ & $\begin{array}{c}B^{*} \\
\text { (in } \\
\text { thousand } \\
\text { tonnes) }\end{array}$ \\
\hline$\alpha_{2} \alpha_{3}=0$ & 0.12 & 0.49 & 235.97 & 56.45 & 181.94 & 767.50 \\
$\alpha_{2} \alpha_{3}<1$ & 0.09 & 0.35 & 223.01 & 56.45 & 180.19 & 739.36 \\
$\alpha_{2} \alpha_{3}>1$ & 0.22 & 0.00 & 206.28 & 56.45 & 177.86 & 702.66 \\
\hline
\end{tabular}

Table note: $\alpha_{2} \alpha_{3}<1$ with $\alpha_{2}=0.2$ and $\alpha_{3}=0.5 . \alpha_{2} \alpha_{3}>1$ with $\alpha_{2}=0.8$ and $\alpha_{3}=1.5$. 